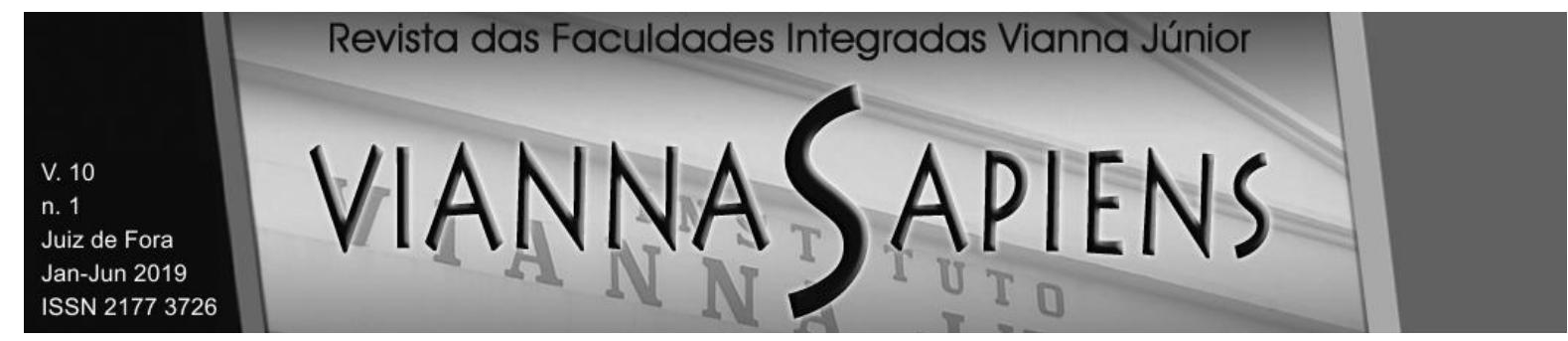

\title{
ADOÇÃO DO MÉTODO BENEISH SCORE NAS EMPRESAS PÚBLICAS BRASILEIRAS DE CAPITAL ABERTO E O IMPACTO NAS SUAS AÇÕES DOI: 10.31994/rvs.v10i1.574
}

\author{
Carolina Corrêa de Albuquerque ${ }^{1}$ \\ Antonio Carlos Magalhães da Silva ${ }^{2}$ \\ Paulo Roberto da Costa Vieira ${ }^{3}$
}

\section{RESUMO}

A análise dos resultados econômico-financeiros de empresas brasileiras públicas de capital aberto pode indicar a existência de gerenciamento de resultados.Dessa forma, o objetivo do trabalho é aplicar a metodologia do Beneish M-Score para a verificação da possibilidade de inconsistência de resultados contábeis. A contribuição deste artigo está na deteç̧ão de aspectos nas empresas geridas pelo Estado que podem permitir a melhoria da gestão pública. A metodologia presente está baseada no trabalho de Beneish e Nichols (2005). A amostra da pesquisa é composta por 17 empresas públicas de capital aberto ao longo de 2005 a 2017 no mercado nacional. Os resultados são associados à análise dos retornos das ações destas empresas no mercado e aspectos relevantes ocorridos nas empresas no ano em que foi detectado indicação pelo modelo adotado. Os resultados obtidos

\footnotetext{
${ }^{1}$ Mestre em Administração e Desenvolvimento Empresarial (MADE/UNESA). Gerente do Bando do Brasil. Email:carolcalbuquerque@ig.com.br - ORCID: https://orcid.org/0000-0002-5616-3840

${ }^{2}$ Professor da Universidade Estácio de Sá (MADE/UNESA) e da Universidade Federal Fluminense (UFF). Bolsista Pesquisa Produtividade da Universidade Estácio de Sá. Doutor em Engenharia de Produção pela Coppe/UFRJ. Email: amagal@uol.com.br - ORCID: https://orcid.org/0000-0003-44973130

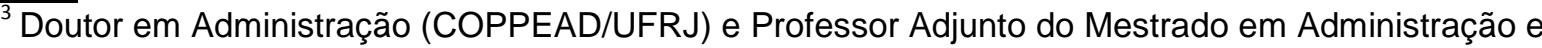
Desenvolvimento Empresarial (MADE/UNESA). E-mail: pvieira2304@gmail.com - ORCID:

https://orcid.org/0000-0003-3742-1127
} 


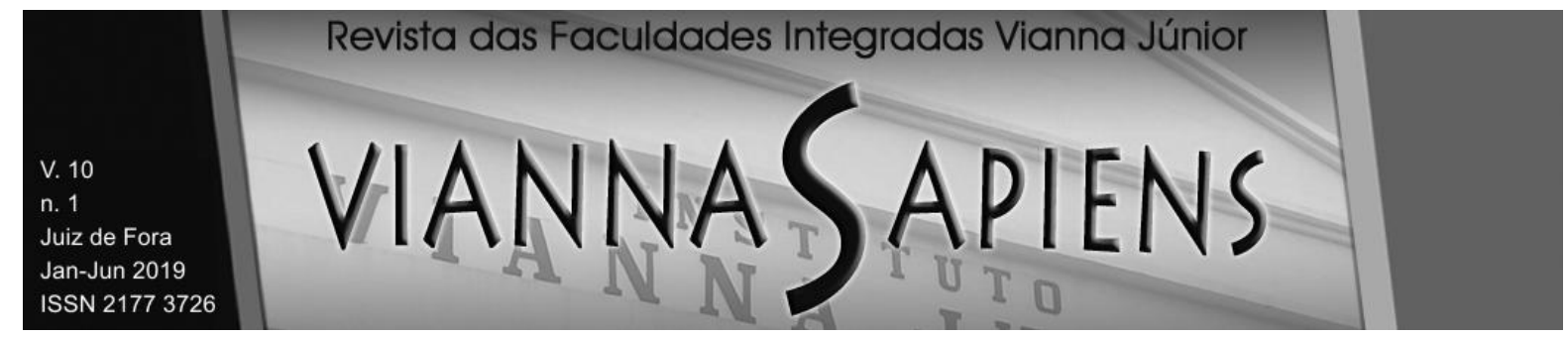

indicaram a possibilidade de inconsistência de resultados recorrentes ao longo de alguns anos em determinadas empresas da amostra, sendo que não foram encontrados resultados que se repetiram ao longo de todo o período estudado.

\title{
PALAVRAS-CHAVE: CORRUPÇÃO, GOVERNANÇA CORPORATIVA E BENEISH MODEL.
}

\begin{abstract}
Thus, the purpose of the paper is to apply the methodology of the Beneish M-Score to verify the possibility of inconsistency of accounting results. The contribution of this article is in the detection of aspects in the companies managed by the State that can allow the improvement of public management. The present methodology is based on the work of Beneish and Nichols (2005). The research sample is composed of 17 publicly traded public companies from 2005 to 2017 in the national market. The results are associated with the analysis of the returns of the actions of these companies in the market and relevant aspects occurred in the companies in the year in which indication was detected by the adopted model. The obtained results indicated the possibility of inconsistency of recurrent results over a few years in certain companies of the sample, and no results were found that were repeated throughout the studied period.
\end{abstract}

KEY WORDS: CORRUPTION. CORPORATE GOVERNANCE. BENEISH MODEL.

\section{INTRODUÇÃO}

Konraht, Soutes e Alencar (2016) destacam o distanciamento existente entre os proprietários/acionistas em comparação aos empregados e gestores (diretoria executiva), que possuem o comando da empresa sob sua responsabilidade para a 


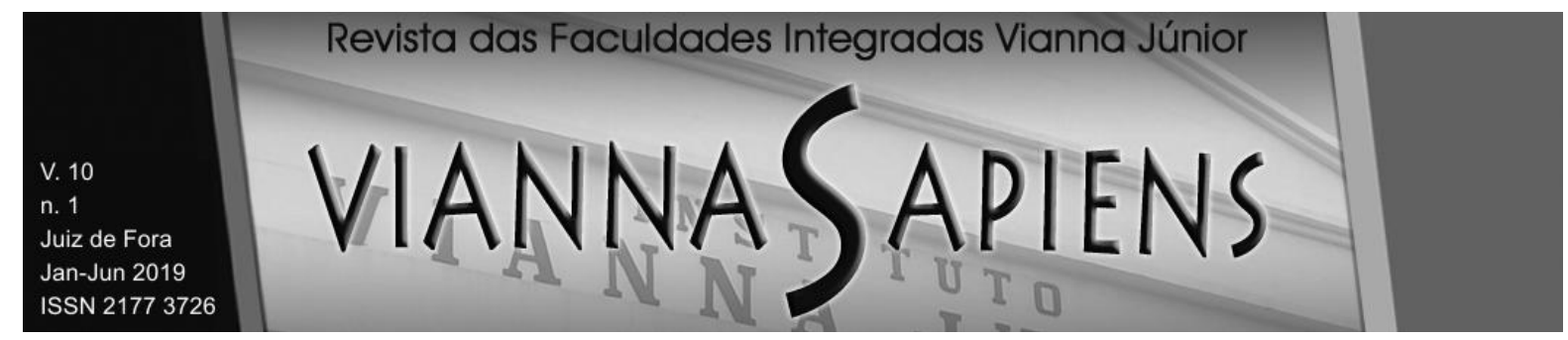

divulgação de resultados de maneira conveniente, pois a informação destinada ao acionista é moldada ao interesse privado do gestor.

Neste sentido, embora a contabilidade atue como um sistema gerador de informações econômicas da empresa por meio da divulgação dos relatórios contábeis, notas explicativas e outras divulgações voluntárias, a contabilidade também pode ser utilizada como instrumento de gerenciamento, uma vez que o administrador pode fazer determinadas escolhas contábeis que alterem o resultado da empresa em determinado período, com a finalidade de obter ganhos particulares ou atender a expectativas contratuais, dentro da legalidade e de acordo com a legislação vigente (DICHEV et al, 2012).

Pinho e Ribeiro (2018) destacam que a corrupção ocorre quando determinado agente (Conselheiro de Administração ou Diretor), que aceitou a obrigação para representar os interesses de um agente principal (Estado), viola ou sacrifica os interesses do líder (Estado) em proveito de seus interesses próprios. Sendo assim, a corrupção estaria configurada nessa questão.

Em outros países, a queda de grandes corporações como Enron, Lehman Brothers, Worldcom, AIG e outras têm atraído atenção no estudo do gerenciamento de resultados. O aumento da crise de confiança nos relatórios financeiros é uma ameaça significativa à existência e à eficiência dos mercados de capitais. (MAHAMA, 2015).

Para identificar os efeitos do gerenciamento em empresas que poderiam se envolver em tal atividade, Beneish (1999) construiu variáveis indicativas por meio de informações contidas nas demonstrações contábeis e que se propõe a verificar a distorções de resultados que podem resultar em gerenciamento de resultados contábeis.

A possibilidade de manipulação de dados é real, e, portanto, a receita, o lucro e o retorno futuro da empresa poderão se rmaiores ou menores, o que pode gerar alterações em seu prêmio de risco com relação ao prêmio de risco negociado no mercado. Assim, se houver a detecção de provável fraude pelo indicador M-Score, a 


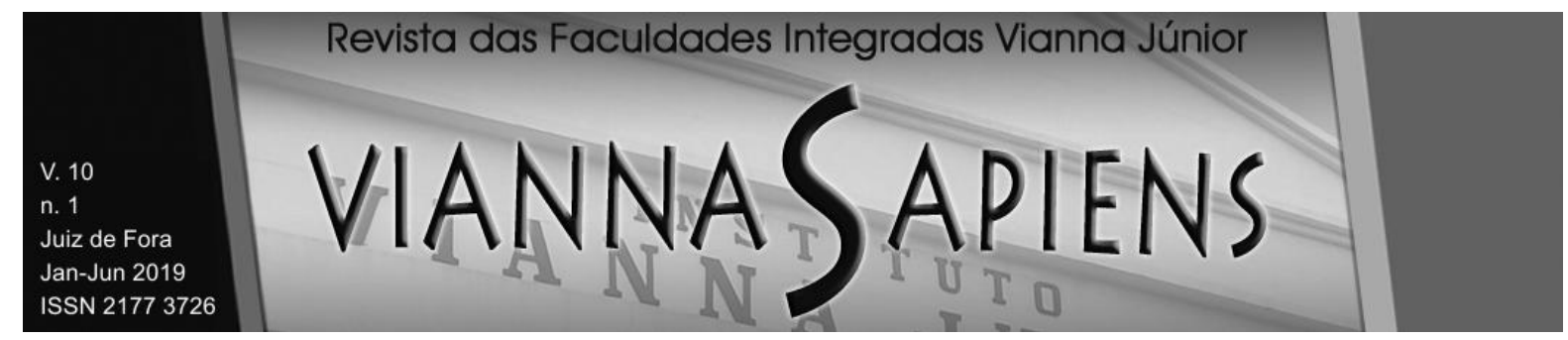

empresa provavelmente estará avaliada indevidamente (BENEISH E NICHOLS, 2005).

Portanto, compreender se existe relação entre um eventual gerenciamento de resultados financeiros por meio da adoção do modelo Beneish M-Score aplicado às empresas públicas brasileiras de capital aberto (sociedade de economia mista) e o resultado das ações negociadas em bolsa, é relevante para a melhoria da gestão pública, permitindo detectar o gerenciamento e, eventualmente, o uso indevido das atribuições a que os agentes do Estado foram incumbidos, e para os tomadores de decisão que utilizam métodos baseados em informações contábeis.

Dessa maneira, o objetivo é averiguar se as empresas públicas brasileiras de capital aberto utilizaram a prática de gerenciamento de resultados, ou seja, verificar se o Método Beneish M-Score pode ser um mecanismo de indicação de possível inconsistência de resultados, e, por conseguinte reduzir a possibilidade de conflitos entre os acionistas e entre os administradores e acionistas.

Este artigo, além desta parte introdutória, está dividido em 4 partes fundamentação teórica, síntese dos resultados, conclusão e referências.

\section{O MODELO DE BENEISH M-SCORE}

O ponto de partida proposto é o modelo Beneish M-score. Esta modelagem, originalmente denominado Manipulation Score, detecta mudanças anormais em lucros entre diferentes períodos, baseado em distorções financeiras de oito variáveis e indica a ocorrência ou predisposição da empresa em ter realizado gerenciamento em seus resultados (CORSI et al., 2015).

A extensão em que os demonstrativos financeiros são manipulados, tem sido uma questão há muito enfrentada pelos órgãos reguladores, stakeholders e auditores (KASSEM; HIGSON, 2012). Desta forma, Omar et al. (2014) defendem que métodos e técnicas como o Beneish M-Score sejam utilizados para possibilitar a detecção para possíveis fraudes. 


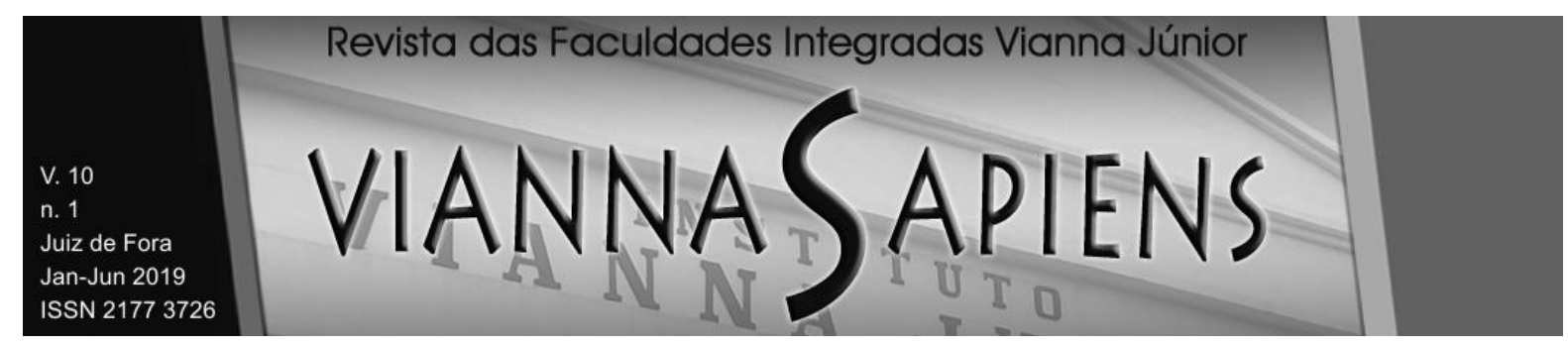

Em reiterados estudos realizados por Beneish et al. (2012), o índice Beneish M-Score detectou que os resultados financeiros de determinadas empresas indicavam a ocorrência de fraude. Nessas mesmas empresas, verificou-se uma valorização de suas ações acima da média de mercado no ano em que o gerenciamento estaria ocorrendo. Após a divulgação dos resultados, em momento posterior, o valor das ações da empresa cai.

O Beneish M-Score é um modelo matemático que adota algumas métricas financeiras para identificar a extensão dos ganhos de uma empresa. Foi desenvolvido para estimar a extensão do gerenciamento de ganhos. A pontuação $M$ (Manipulation) é composta por oito índices que captam distorções nas demonstrações financeiras que podem resultar no gerenciamento de ganhos (MAHAMA, 2015). Beneish (1999) indica que as empresas com maior pontuação são mais susceptíveis de serem manipuladoras.

Anh et al. (2016) discorrem que o modelo Beneish M-Score foi desenvolvido com base em estudo de 74 empresas dos EUA durante 10 anos (1982-1992). Na amostra para desenvolver o modelo, identificou-se corretamente $76 \%$ dos manipuladores, enquanto apenas, incorretamente, $17,5 \%$ de não-manipuladores. Este trabalho descreveu que o modelo Beneish M-Score também provou seu poder na detecção de gerenciamento de resultados nos países em desenvolvimento, fornecendo uma ferramenta confiável para os investidores tomarem decisões e verificarem a confiabilidade das informações contábeis em relatórios financeiros, mesmo após a realização de auditorias independentes.

Nas empresas italianas, Corsi et al (2015), com intuito de analisar os efeitos do modelo Beneish na sinalização das empresas manipuladoras, analisaram uma amostra extraída do banco de dados da rede italiana Netval.

Tarjo (2015) analisou, com base no teste de mineração de dados (data mining) utilizando regressão logística, que a acurácia do modelo Beneish M-Score para detectar fraudes foi de $77,1 \%$ (27 de 35 empresas que cometeram fraudes). No entanto, a constatação interessante no seu estudo é que empresas que não 


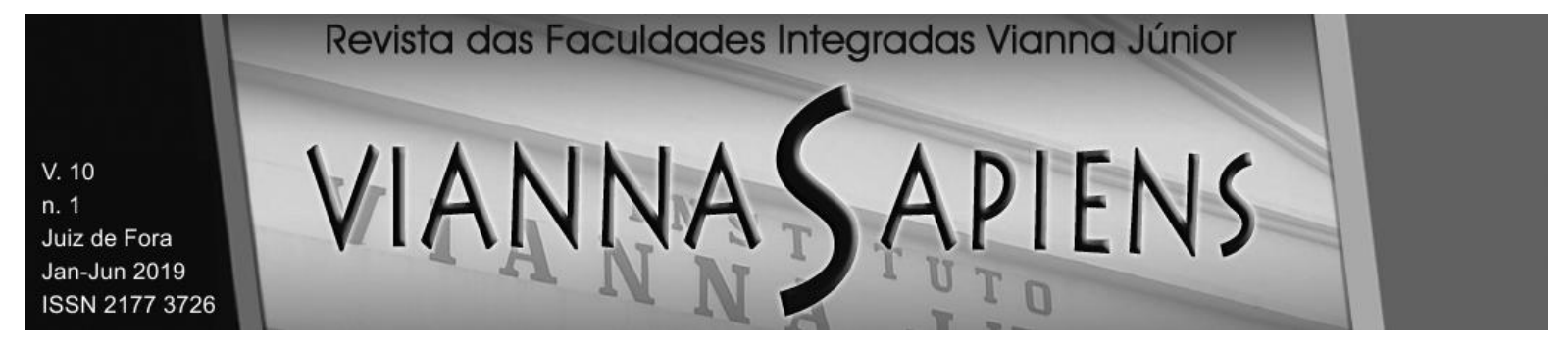

cometeram gerenciamento podem ser indicadas pelo modelo como prováveis manipuladoras de resultados.

$\mathrm{Na}$ Grécia, Repousis (2016), avaliou as demonstrações financeiras de instituições financeiras por meio da adoção do modelo desenvolvido por Beneish em uma amostra de 8.486 companhias. Detectou gerenciamento em $33 \%$ delas.

Beneish e Nichols (2007) categorizam ainda os oito índices em dois: as razões preditivas com foco nas distorções das demonstrações contábeis e as razões preditivas que sugerem condições propícias para o gerenciamento. Assim, para cada um dos oito índices, pode-se descrever o raciocínio que permite utilizá-lo como um percussor de eventuais manipulações ou gerenciamento de dados.

A seguir apresentamos a composição dos indicadores presentes no Modelo de Beneish M-Score

\section{1 Índice de Vendas Diárias e Recebíveis (DSRI)}

Esse índice mede a proporção de dias que as vendas estão em contas a receber em um ano em comparação com o ano anterior. A variável mede se recebíveis e receitas estão dentro ou fora de equilíbrio em dois anos consecutivos (ANH et al., 2016).

\section{2 Índice de Vendas Diárias e Recebíveis (DSRI)}

Mahama (2015) descreve o índice de margem bruta como a medida entre a margem bruta do ano anterior e a do ano em análise. Quando o GMl é maior que 1,0 significa que a margem bruta piorou no período em análise, com a consequência de que a empresa provavelmente gerenciou suas receitas. 


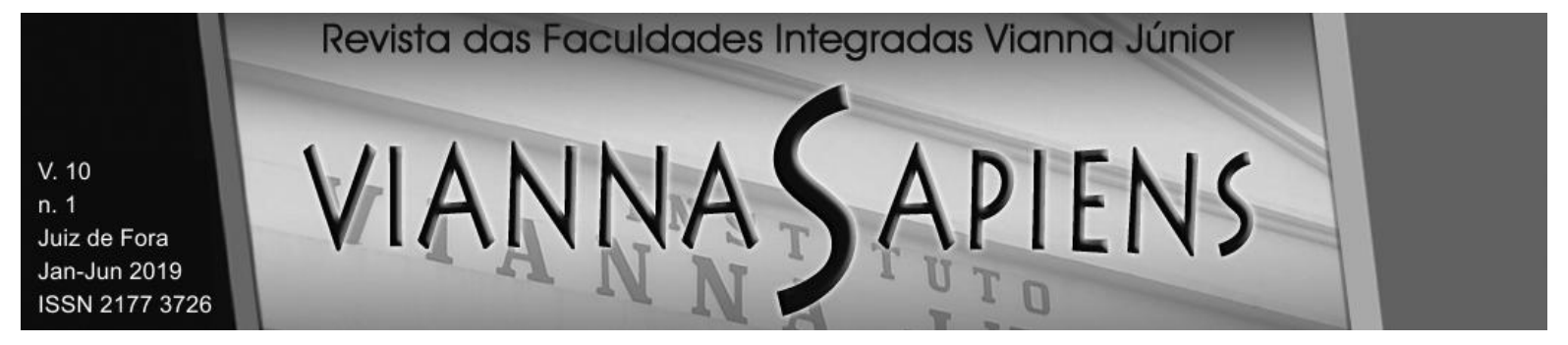

\section{3 Índice de qualidade de ativos (AQI)}

Para Beneish (1999), a qualidade do ativo em um determinado ano é a relação entre os ativos não circulantes (excluindo-se também o imobilizado) e o ativo total e mede a proporção do total de ativos para os quais os benefícios futuros são potencialmente menos certos. Se AQI for maior que 1 , isso indica que a empresa aumentou potencialmente seu envolvimento no diferimento de custos ou aumentou seus ativos intangíveis e gerou ganhos de gerenciamento.

\section{4 Índice de Crescimento de Vendas (SGI)}

A métrica é uma medida do crescimento das vendas em um ano sobre a receita de vendas do ano anterior. O crescimento não implica gerenciamento, mas Beneish (1999) declara que as empresas em crescimento seriam mais propensas a cometerem fraudes nas demonstrações financeiras, porque sua posição financeira e necessidades de capital pressionam os administradores a alcançar metas de ganhos.

\section{5 Índice de Depreciação (DEPI)}

O índice de depreciação é uma medida do índice de despesa de depreciação e valor bruto de imobilizado em um ano em relação ao ano anterior. Um índice acima de 1,0 indica que a taxa de depreciação dos ativos diminuiu, o que poderia ser um reflexo de um ajuste para cima da vida útil dos imobilizados ou adotado um novo método em que os lucros estão aumentando. Isso tem a tendência de os ganhos de uma empresa serem manipulados no ano em análise (MAHAMA, 2015). 


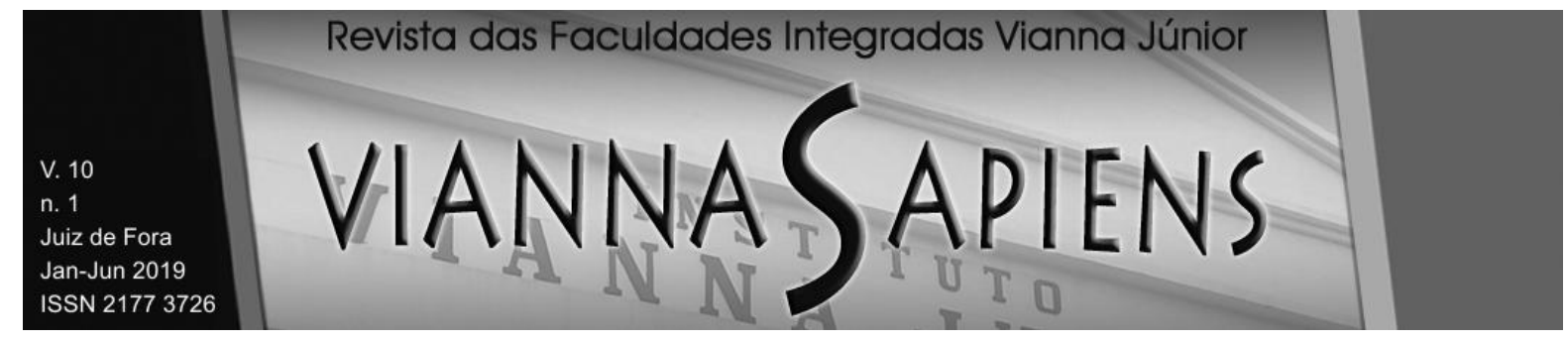

\section{6 Índice de Despesas Gerais, Administrativas e de Vendas (SGAI)}

A SGAI é calculada como a razão entre o SGA e as vendas no ano t em relação à medida correspondente no ano t-1. Warshavsky (2012) discorre que os analistas interpretariam um aumento desproporcional nas vendas como um sinal negativo sobre as perspectivas futuras das empresas. Espera-se uma relação positiva entre a SGAI e a probabilidade de gerenciamento.

\section{7 Índice de Acréscimos ao Ativo Total (TATA)}

Este índice é usado para medir até que ponto as vendas são feitas em regime de caixa. Warshavsky (2012) discorre que precisamente quando a avaliação do fluxo de caixa falha que os gerentes têm um incentivo para gerenciar as receitas, a fim de aumentar a capitalização do mercado.

\section{8 Índice de alavancagem (LEVI)}

O índice de alavancagem é a razão entre a dívida total e o total de ativos no ano t em relação ao índice correspondente no ano t-1. Beneish (1999) assume que a alavancagem segue uma caminhada aleatória, e, a mudança na alavancagem na estrutura de capital das empresas para um patamar superior, normalmente está associada ao efeito de inadimplência do mercado de ações.

\section{9 Índice de alavancagem (LEVI)}

O indicador de Beneish é apresentado de acordo com a seguinte equação: $\mathrm{M}=-4.84+0.920 \mathrm{DSR}+0.528 \mathrm{GMI}+0.404 \mathrm{AQI}+0.892 \mathrm{SGI}+0.115 \mathrm{DEPI}-0.172 \mathrm{SGAI}$ + 4.679TATA - 0.327LEVI

Da análise dos índices que compõe o Beneish M-Score, BENEISH (2005) demonstra que há índices preditivos focados nas distorções das demonstrações 


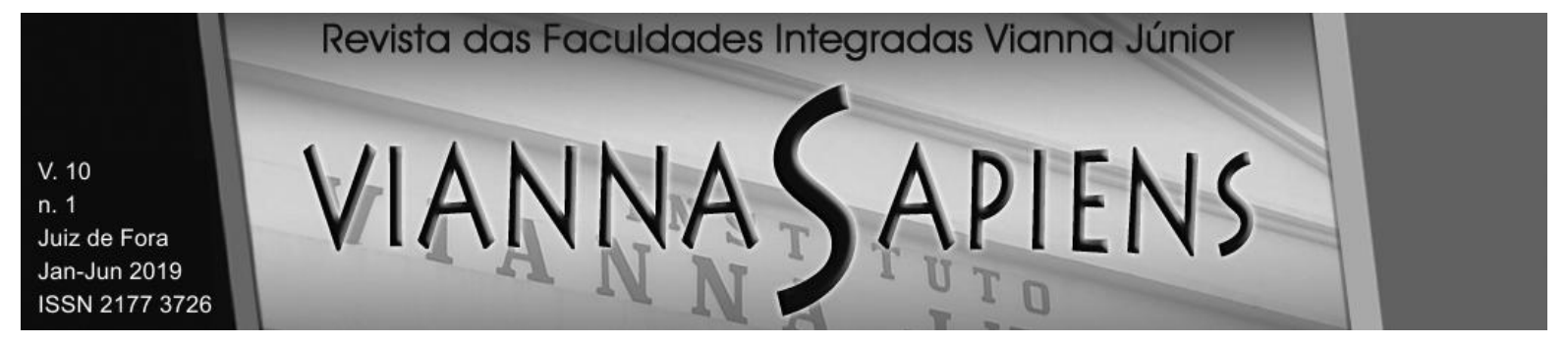

contábeis que capturam acumulações incomuns nos recebíveis (Índices de venda DSRI, indicativo de inflação de receita), capitalização incomum de despesas e declínios na depreciação (qualidade do ativo - AQI e depreciação - DEPI, ambos indicativos de deflação de despesas). Para fins de comparação com outros modelos, Mahama (2015) compara o Beneish M-Score com o Z-Score de Altman, muito utilizado na área de risco de crédito.

O M-Score indica que existe a possibilidade de manipulação para valores superiores a -2,22, de acordo com o trabalho de Beneish (2005).

\section{RISCO E RETORNO}

Foi utilizado o modelo do CAPM (capital asset pricing model) que se caracteriza como um modelo de risco e retorno que mede a exposição ao risco por um Beta $(\beta)$ do mercado, identificado como o coeficiente angular de uma regressão linear dos retornos do ativo em relação aos retornos da carteira diversificada de mercado (FIORESI; GALDI, 2017). O CAPM implica que o retorno esperado de um ativo é igual à taxa livre de risco mais o prêmio de risco de mercado multiplicado pelo Beta desse ativo:

$E(R i)=R_{r f}+\beta_{i}\left(E\left(R_{m t}\right)-R_{r f}\right)$

Onde:

$E\left(R_{i}\right)=$ retorno esperado do ativo ou carteira $i$;

$\mathrm{R}_{\mathrm{rf}}=$ taxa livre de risco;

$\beta_{i}\left(E\left(R_{m t}\right)-R_{r f}\right)=$ prêmio de risco do ativo (Beta do ativo com relação ao portfólio de mercado multiplicado pelo prêmio de risco deste);

$\beta_{i}=$ Beta, medida de risco sistemático, ou seja, medida de risco perante às oscilações do mercado, dado que mensura a sensibilidade entre os retornos do ativo e do mercado; é medido pela covariância do retorno do ativo de uma empresa e o retorno em excesso do mercado 


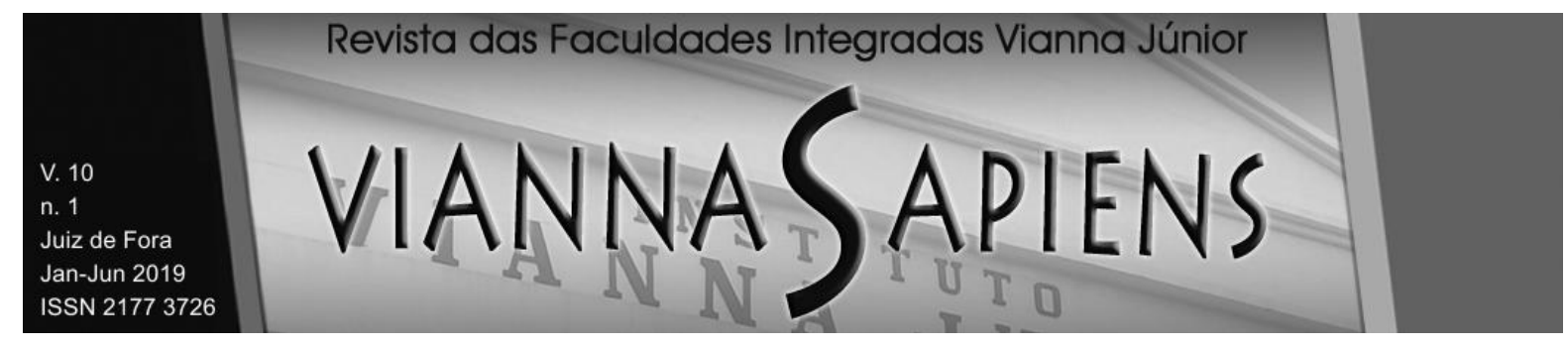

Jensen (1967) visualizou a possibilidade de realizar uma regressão de série temporal utilizando o CAPM. Compara o retorno observado de um investimento com o retorno que esse investimento deveria ter realizado ao longo do período de avaliação, dado o seu Beta e o comportamento do mercado ao longo do período.

$R_{i}-R_{r f}=\alpha i+\beta_{i}\left(R_{m}-R_{r f}\right)+\varepsilon_{i}$

Onde

$\alpha i=$ Alfa de Jensen;

$\varepsilon_{\mathrm{i}}=$ termo de erro, sendo serialmente independente e tendo $E\left(\varepsilon_{\mathrm{i}}\right)=0$.

O Alfa representa a taxa média incremental do retorno por unidade de tempo que se deve exclusivamente aos excessos de retorno dos ativos, também chamado de Retornos Excedentes ou Retornos Anormais e um valor significativamente maior que zero indica que a estratégia apresenta retornos acima da média do mercado mesmo quando ajustado ao risco (FIORESI; GALDI, 2015).

O valor do Beta e do Alfa das ações em relação ao índice de mercado foram calculados adotando como parâmetro de mercado o índice Bovespa e como taxa livre de risco o CDI (Certificado de Depósito Interbancário).

\section{METODOLOGIA}

O presente trabalho foi realizado com base na coleta de dados secundários das demonstrações financeiras anuais para o período de 2005 a 2017. Foram escolhidas as empresas listadas na B3 com controle do estado, sendo que era necessário um mínimo de free float ${ }^{4}$ de $10 \%$ para participação em nossa amostra. A seguir expomos as empresas que fizeram parte do trabalho:

- Banco do Brasil

- Banco do Estado de Sergipe (Banese)

- Banco do Estado do Rio Grande do Sul (Banrisul)

- Companhia Energética de Brasília (CEB)

\footnotetext{
${ }^{4}$ Ações livres e disponíveis para negociação em bolsa que não pertencem ao bloco controlador.
} 


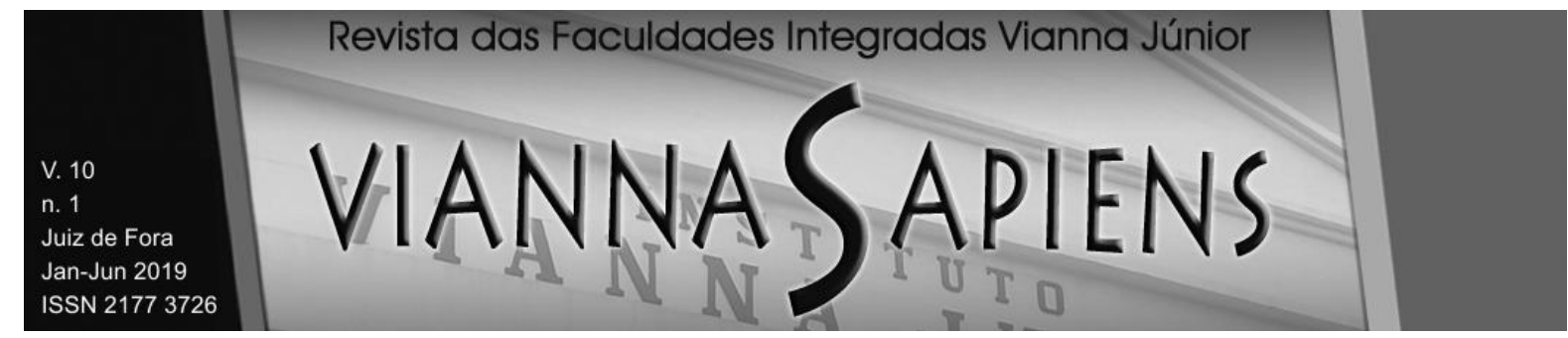

- Companhia Estadual e Energia Elétrica do Rio Grande do Sul (CEEE)

- Centrais Elétricas de Santa Catarina (Celesc)

- Centrais Elétricas de Minas Gerais SA (Cemig)

- Companhia Energética de São Paulo (CESP)

- Companhia de Saneamento de Minas Gerais (Copasa)

- Companhia Paranaense de Energia (Copel)

- Centrais Elétricas Brasileiras S.A (Eletrobrás)

- Empresa Metropolitana Energias S.A (EMAE)

- Petróleo Brasileiro S.A (Petrobras)

- Companhia de Saneamento Básico do Estado de São Paulo (Sabesp)

- Companhia de Saneamento do Paraná (Sanepar)

- Transmissora Aliança de Energia Elétrica S.A (Taesa)

- Telecomunicações Brasileiras S.A (Telebras)

Além do cálculo dos indicadores de Beneish para cada empresa ao fim de cada ano, também foram calculados o risco e o retorno das ações em cada período, serão utilizados o Índice Beta e o Alfa de Jensen. Após essa etapa, é realizada a análise caso a caso de cada empresa pelo índice de Beneish e a sua respectiva avaliação de risco retorno.

\section{SÍNTESE DOS RESULTADOS E DISCUSSÕES}

A seguir, apresentam-se as tabelas com os retornos no mercado acionário das empresas.

\section{Banco do Brasil S.A. (BB)}

Tabela 2 - Índices Beneish M-Score, Alfa e Beta do BB

\begin{tabular}{lc|c|c|c|c|c|c|c|c|c|c|c}
\hline BB & 2006 & 2007 & 2008 & 2009 & 2010 & 2011 & 2012 & 2013 & 2014 & 2015 & 2016 & 2017 \\
\hline DSRI & 1,07 & 1,03 & 1,03 & 1,27 & 0,92 & 0,97 & 1,23 & 0,95 & 0,83 & 0,75 & 1,04 & 1,10 \\
GMI & 0,90 & 1,28 & 0,60 & 1,19 & 1,24 & 0,83 & 1,01 & 0,86 & 0,75 & 0,46 & 2,31 & 0,97 \\
AQI & 0,99 & 0,88 & 1,01 & 0,96 & 0,99 & 0,99 & 1,14 & 0,94 & 0,97 & 1,08 & 0,94 & 1,03 \\
SGI & 1,11 & 1,10 & 1,38 & 1,01 & 1,29 & 1,25 & 1,01 & 1,14 & 1,29 & 1,35 & 0,91 & 0,91
\end{tabular}




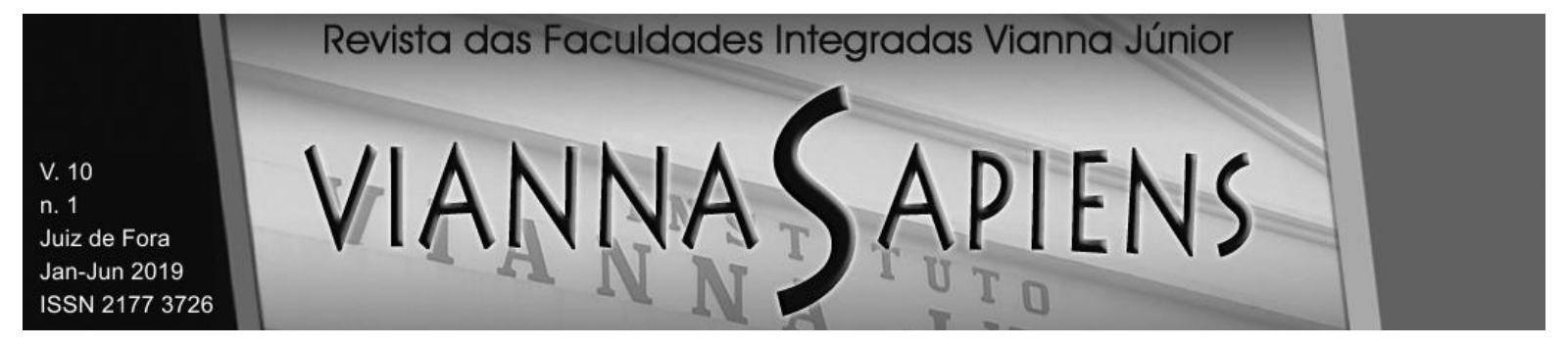

\begin{tabular}{|c|c|c|c|c|c|c|c|c|c|c|c|c|}
\hline EPI & ,04 & 1,38 & 0,00 & 0,00 & 0,00 & 0,00 & 0,00 & 0,00 & 0,00 & 0,00 & 0,00 & 0,00 \\
\hline Al &, 10 & 1,56 &, 11 & ,99 & 1,32 & 0,91 & 1,16 & 1,18 & 0,64 & 0,75 & ,64 & ),87 \\
\hline ATA &, 44 & $-0,46$ & $-0,39$ & $-0,35$ & $-0,34$ & $-0,30$ & $-0,30$ & $-0,29$ & 0,27 & $-0,28$ & $-0,28$ & $-0,29$ \\
\hline$/ \mathrm{Gl}$ & 1,00 & 1,00 & 1,01 & 1,01 & 0,99 & 1,00 & 1,00 & 00 & 1,00 & , 00 & 00 & 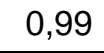 \\
\hline $1-S$ & 1,45 & $-4,45$ & $-4,12$ & $-4,41$ & $-3,95$ & $-3,86$ & $-3,73$ & $-4,00$ & $-3,84$ & $-4,03$ & $-3,36$ & $-3,91$ \\
\hline Ifa & 0,28 & 0,07 & 0,02 & 0,26 & 0,12 & $-0,01$ & , & 0,17 & $\begin{array}{l}0,21 \\
\end{array}$ & 0,00 & 0,33 & $-0,14$ \\
\hline Beta & 13 & 0,96 & 1,11 & 0,90 & 0,93 & 10 & ו & 0,71 & 1 & $16 ?$ & 1,67 & 1,68 \\
\hline & $33 \%$ & $44 \%$ & $-41 \%$ & $83 \%$ & $1 \%$ & $-18 \%$ & $7 \%$ & $-15 \%$ & $-3 \%$ & $-13 \%$ & $39 \%$ & $7 \%$ \\
\hline & $\%$ & $47 \%$ & & & $\%$ & & & $5 \%$ & & & & \\
\hline
\end{tabular}

Em relação ao BB, o Índice Beneish M-Score não detectou nenhum indício de gerenciamento de resultados no período analisado (todos foram inferiores a -2,22). O comportamento de suas ações em relação ao lbovespa refletiu uma volatilidade (risco) próxima / superior à de mercado com tendência de elevação ao longo dos anos. O Alfa demonstra que o BB superou o retorno de mercado na maioria os anos, com desvio padrão de 0,13 e média de 0,12 .

\section{Banco do Estado de Sergipe (Banese)}

Tabela 3 - Índices Beneish M-Score, Alfa e Beta do Banese

\begin{tabular}{|c|c|c|c|c|c|c|c|c|c|c|c|c|}
\hline BAN & 006 & 2007 & 2008 & 2009 & 2010 & 2011 & 012 & 2013 & 014 & 2015 & 016 & 017 \\
\hline D & & & & & & & & & & & & \\
\hline $\mathrm{G}$ & 1,03 & 1,05 & 0,80 & 0 & & 1,01 & 1,11 & 90 & 0,80 & 1,01 & 0,92 & 77 \\
\hline AQI & 1,46 & 0,94 & 1,09 & 1,17 & 0,78 & 0,93 & 0,86 & 1,29 & 0,88 & 95 & 0,97 & 0,90 \\
\hline SGI & 1,1 & 1,04 & 1,19 & 1,12 & 1, & 1,36 & 1,05 & 0,92 & 1,10 & ర & 10 & 1,05 \\
\hline DEPI & 0,00 & 0,00 & 0,00 & 0,00 & 0, & 0,00 & 0,00 & 0,00 & 0,00 & 0,00 & 0,00 & 0,00 \\
\hline SG & 1,10 & 0,90 & 0,85 & 1,00 & 1, & 0,80 & 1,09 & 1,12 & 1,08 & 1,86 & 1,01 & 1,04 \\
\hline TATA & $-0,55$ & $-0,57$ & $-0,49$ & $-0,54$ & $-0,54$ & $-0,57$ & $-0,59$ & $-0,58$ & $-0,62$ & $-0,58$ & $-0,59$ & $-0,60$ \\
\hline LVGI & 1,01 & 1,01 & 1,01 & 0,99 & 1,00 & 0,99 & 0,99 & 1,01 & 1,01 & 1,00 & 1,00 & 1,00 \\
\hline M-s & 4,50 & $-5,09$ & $-4,51$ & $-4,94$ & $-5,00$ & $-4,92$ & $-5,33$ & $-5,38$ & $-5,61$ & $-5,17$ & $-5,42$ & $-5,26$ \\
\hline Alfa & 1,42 & م-0 & $-0,38$ & 0 & , & 0,6 &, $12 !$ & 0,07 & $0_{3}$ & . & 0,24 & 0 \\
\hline Beta & 0,02 & 0,06 & 0,01 & $-0,18$ & 0,16 & $-0,14$ & 0,01 & 0,06 & 0,04 & 0,05 & 0,19 & 0 \\
\hline lbove & $33 \%$ & $44 \%$ & $-41 \%$ & $83 \%$ & $1 \%$ & $-18 \%$ & $7 \%$ & $-15 \%$ & $-3 \%$ & $-13 \%$ & $39 \%$ & $27 \%$ \\
\hline a & 80 & $-5 \%$ & $42 \%$ & $40 \%$ & 12 & $a c$ & 20 & 130 & $-27 \%$ & -2 & $46 \%$ & 1390 \\
\hline
\end{tabular}

Fonte: Autores 


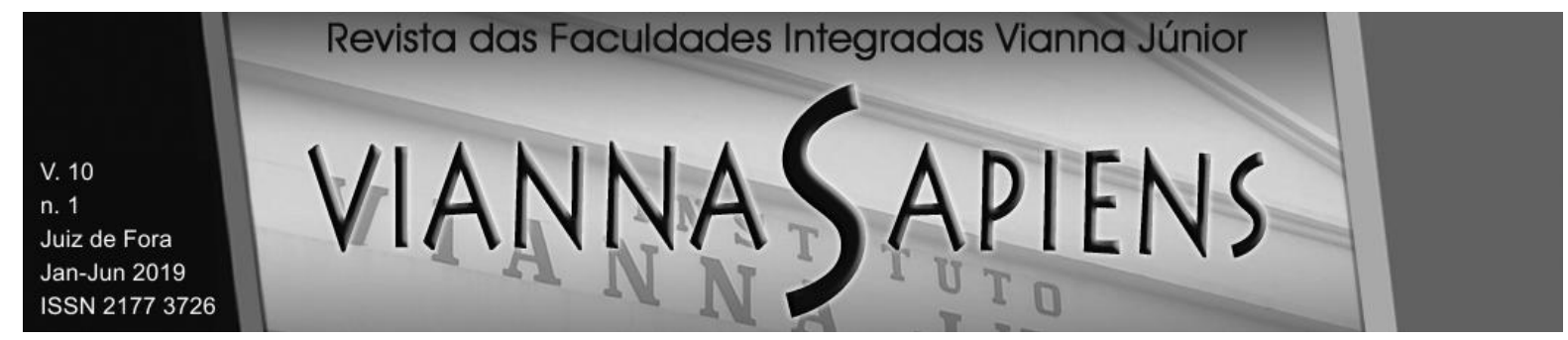

Em relação ao Banese, Índice Beneish M-Score não detectou nenhum indício de gerenciamento de resultados. O comportamento de suas ações em relação ao lbovespa apresentou um risco descorrelacionado ao de mercado. O Alfa não apresentou tendência clara, com desvio padrão de 0,55 e média de 0,16.

\section{Banco do Estado do Rio Grande do Sul (Banrisul)}

Tabela 4 - Índices Beneish M-Score, Alfa e Beta do Banrisul

\begin{tabular}{|c|c|c|c|c|c|c|c|c|c|c|c|c|}
\hline BANRISUL & 2006 & 2007 & 2008 & 2009 & 2010 & 2011 & 2012 & 2013 & 2014 & 2015 & 2016 & 2017 \\
\hline DSRI & 1,53 & 1,34 & 0,89 & 1,11 & 1,08 & 1,03 & 1,04 & 1,29 & 0,88 & 0,81 & 0,94 & 0,88 \\
\hline GMI & 1,01 & 0,90 & 0,92 & 1,13 & 0,99 & 0,93 & 0,99 & 1,01 & 0,80 & 0,72 & 1,24 & 1,16 \\
\hline AQI & 1,96 & 0,89 & 0,87 & 1,15 & 1,12 & 1,11 & 0,91 & 1,27 & 0,99 & 0,97 & 0,95 & 0,71 \\
\hline SGI & 1,07 & 0,87 & 1,35 & 1,10 & 1,13 & 1,23 & 1,07 & 1,04 & 1,24 & 1,32 & 0,99 & 0,94 \\
\hline DEPI & 0,00 & 0,00 & 0,00 & 0,00 & 0,00 & 0,00 & 0,00 & 0,00 & 0,00 & 0,00 & 0,00 & 0,00 \\
\hline SGAI & 1,00 & 1,20 & 0,83 & 1,02 & 0,95 & 0,88 & 1,06 & 1,11 & 0,90 & 0,82 & 1,12 & 1,18 \\
\hline TATA & 0,00 & 0,00 & $-0,03$ & $-0,01$ & 0,10 & 0,00 & $-0,01$ & 0,10 & 0,01 & $-0,02$ & $-0,05$ & 0,00 \\
\hline LVGI & 1,00 & 0,94 & 1,02 & 1,01 & 1,00 & 1,00 & 1,01 & 1,01 & 1,00 & 1,00 & 1,00 & 1,00 \\
\hline M-score & $-1,66$ & $-2,52$ & $-2,61$ & $-2,35$ & $-1,86$ & $-2,33$ & $-2,61$ & $-1,73$ & $-2,53$ & $-2,72$ & $-2,80$ & $-2,85$ \\
\hline Alfa & & T & $-0,19$ & 0,64 & 0,23 & 0,42 & $-0,20$ & $-0,01$ & 0,27 & $-0,64$ & 0,18 & 0,16 \\
\hline Beta & & & 0,68 & 0,76 & 0,75 & 11,04 & 1,41 & 0,77 & 1,12 & 0,88 & 1,60 & 11,81 \\
\hline Ibovespa & $33 \%$ & $44 \%$ & $-41 \%$ & ! $83 \%$ & $1 \%$ & $-18 \%$ & : $7 \%$ & $-15 \%$ & :-3\% & $-13 \%$ & , 39\% & $27 \%$ \\
\hline Empresa & & ו & $-44 \%$ & $181 \%$ & $26 \%$ & $18 \%$ & $-18 \%$ & $-15 \%$ & $23 \%$ & $-55 \%$ & $89 \%$ & $51 \%$ \\
\hline
\end{tabular}

Fonte: Autores

O Banrisul apresentou, em 2006, índice de qualidade de ativos e índice de vendas diárias e recebíveis nos maiores níveis da série. Desta forma, a um mesmo custo, teria mais geração de receita e a qualidade de seus ativos estaria melhor. Beneish (1999) discorre que empesas em dificuldade normalmente manipulam estes índices para superestimá-los. Ocorre que o ano de 2006 estava com crédito aquecido, o que justificou a magnitude do resultado. Importa destacar que o Banrisul abriu capital em 2007 e a falência do Lehman Brothers ocorreu em setembro de 2008. Portanto, não será considerado o ano do gerenciamento para a conclusão deste trabalho. 


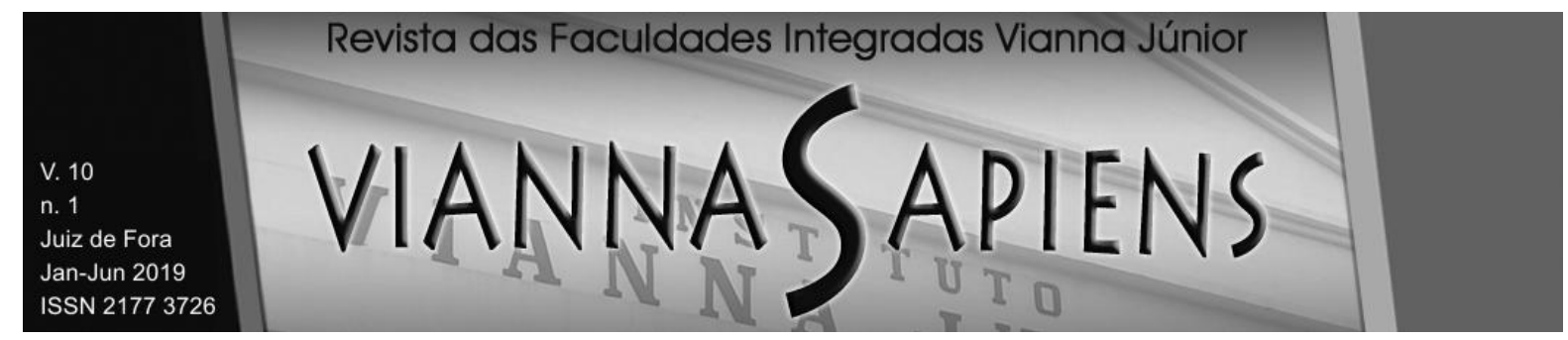

Em 2010 e 2013 há novamente indícios de gerenciamento de resultados. O destaque é o índice de ativos totais (TATA), que atingiu seu máximo nos dois períodos. Sem deixar de considerar os demais fatores, como seu multiplicador no Índice Beneish M-Score é relevante, seu impacto acabou sendo maior. Nesse indicador, é refletida a variação do capital de giro, em relação ao caixa, gastos, impostos a pagar e depreciação.

Importante ressaltar que o aumento da liquidez no Brasil decorrente das políticas para fomentar o crédito que permaneceram em vigor após 2008 (MORA, 2015), pode, no caso de bancos, ter ocasionado expressivo aumento em depósitos à vista. Ainda, seria necessário verificar o crescimento da economia, pois variações bruscas no PIB poderiam trazer índices positivos que levariam o indicativo de gerenciamento de resultados.

O risco (Beta) seguiu uma tendência de correlação positiva com a Bolsa (risco um pouco inferior ou superior ao de mercado), enquanto o Alfa não apresentou tendência definida. O Alfa, na série, apresenta média de 0,17 e desvio padrão de 0,40 .

\section{Companhia Energetica de Brasília (CEB)}

Tabela 5 - Índices Beneish M-Score, Alfa e Beta da CEB

\begin{tabular}{lc|c|c|c|c|c|c|c|c|c|c|c}
\hline CEB & 2006 & 2007 & 2008 & 2009 & 2010 & 2011 & 2012 & 2013 & 2014 & 2015 & 2016 & 2017 \\
\hline DSRI & 0,00 & 0,00 & 0,53 & 1,69 & 0,50 & 2,98 & 0,16 & 1,22 & 4,06 & 0,85 & 1,99 & 0,77 \\
GMI & 1,00 & 1,00 & 1,00 & 1,00 & 0,88 & 0,00 & 101,45 & 0,48 & 0,77 & 0,62 & 2,28 & 1,98 \\
AQI & 0,00 & 0,00 & 0,02 & 14,20 & 11,54 & 1,00 & 1,03 & 1,49 & 1,31 & 1,38 & 4,88 & 0,90 \\
SGI & 0,09 & 0,42 & 1,52 & 0,99 & 1,47 & 0,39 & 1,65 & 0,85 & 1,80 & 0,37 & 1,41 & 1,39 \\
DEPI & 0,00 & 1,08 & 0,00 & 0,00 & 0,00 & 0,00 & 0,00 & 0,00 & 0,00 & 0,00 & 0,00 & 0,00 \\
SGAI & 1,63 & 1,23 & 0,37 & 3,22 & 0,33 & 1,29 & 1,01 & 2,50 & 0,66 & 1,41 & 0,89 & 1,31 \\
TATA & 0,20 & $-0,10$ & 0,19 & 0,11 & 0,00 & 0,04 & 0,00 & 0,08 & 0,16 & 0,02 & 0,11 & 0,08 \\
LVGI & 0,64 & 0,35 & 0,23 & 3,61 & 1,50 & 0,97 & 1,96 & 1,30 & 1,25 & 0,27 & 0,93 & 0,96 \\
\hline M-score & $-3,79$ & $-4,61$ & $-1,72$ & 2,66 & 1,54 & $-1,70$ & 49,95 & $-2,57$ & 1,65 & $-3,09$ & 1,46 & $-1,67$ \\
\hline Alfa & 0,48 & 0,59 & $-0,07$ & 0,06 & 0,13 & 0,30 & $-0,17$ & $-0,33$ & $-0,27$ & $-0,06:-0,19:-0,01$ \\
\hline Beta & 0,11 & 0,19 & 0,09 & 0,07 & 0,04 & 0,07 & $-0,05$ & $-0,01$ & $-0,02$ & 0,00 & 0,02 & 0,01 \\
\hline Ibovespa & $33 \%$ & $44 \%$ & $-41 \%$ & $83 \%$ & $1 \%$ & $-18 \%$ & $7 \%$ & $-15 \%$ & $-3 \%$ & $-13 \%$ & $39 \%$ & $27 \%$ \\
\hline
\end{tabular}




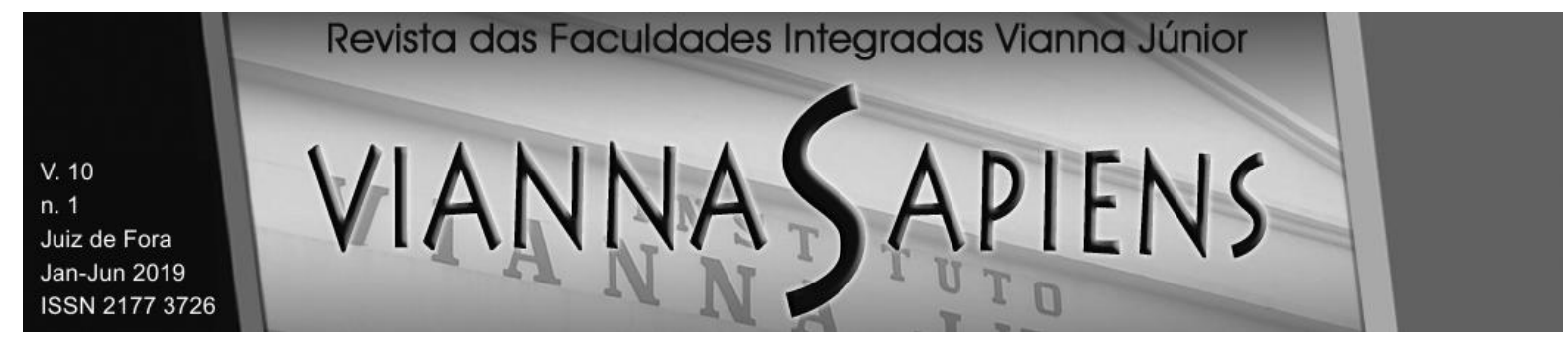

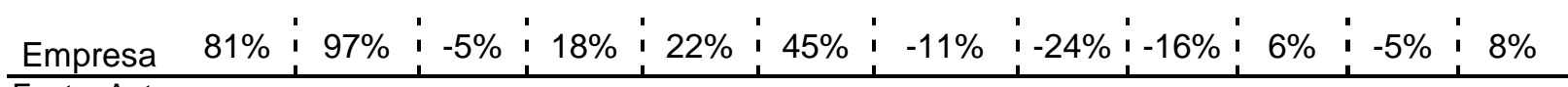
Fonte: Autores

A CEB apresentou anos consecutivos de indicação de gerenciamento de resultados pelo modelo de $\mathrm{M}$ Beneish. Destaque-se índices muito elevados de recebíveis e vendas diária, de margem bruta, de qualidade de ativos e de despesas gerais, administrativas e vendas. O comportamento de suas ações em relação ao lbovespa apresentou um risco não correlacionado ao de mercado por meio da análise do Beta. O Alfa não apresentou tendência clara, com desvio padrão de 0,76 e média de 0,12.

Entretanto, por meio das colunas de retorno do lbovespa e da Empresa, verifica-se que, de 2008 até 2017 a Empresa valorizou-se 39\% enquanto o lbovespa obteve 66\%. Ainda, da data em que o índice atingiu seu maior valor (2012) até 2017, a empresa perdeu $31 \%$ do seu valor de mercado e o lbovespa obteve retorno positivo de $34 \%$.

De acordo com o Relatório da Administração de 2012 da CEB Distribuição SA (2018), a Companhia possuía um saldo a receber bastante significativo, e busca uma agressiva política de cobrança junto aos devedores para reduzir substancialmente as suas contas a receber em atraso.

A Administração da CEB declarou em seu Relatório de Administração que vem se comprometendo nos esforços na recuperação da Companhia.

\section{Companhia Estadual e Energia Elétrica do Rio Grande do Sul (CEEE)}

Tabela 6 - Índices Beneish M-Score, Alfa e Beta da CEEE

\begin{tabular}{ll|c|c|c|c|c|c|c|c|c|c|c}
\hline CEEE & 2006 & 2007 & 2008 & 2009 & 2010 & 2011 & 2012 & 2013 & 2014 & 2015 & 2016 & 2017 \\
\hline DSRI & 0,26 & 0,70 & 4,07 & 1,12 & 0,86 & 0,60 & 0,99 & 0,93 & 0,50 & 1,13 & 1,00 \\
GMI & 0,52 & 1,36 & 0,70 & 0,77 & 1,57 & 0,26 & $-0,42$ & $-0,67$ & $-5,80$ & 1,72 & 0,21 \\
AQI & 0,98 & 0,90 & 2,56 & 1,22 & 0,53 & 0,85 & 1,57 & 1,14 & 0,36 & 0,81 & 1,01 \\
SGI & 3,79 & 1,18 & 1,01 & 1,12 & 1,12 & 1,08 & 1,03 & 1,26 & 1,19 & 0,82 & 1,11 \\
DEPI & 3,72 & 1,02 & 0,97 & 1,83 & 1,11 & 0,86 & 1,27 & 1,07 & 0,20 & 1,77 & 1,02 \\
SGAI & 0,22 & 1,35 & 1,42 & 0,74 & 1,00 & 0,53 & 1,11 & 1,29 & 0,56 & 0,94 & 0,12 \\
TATA & $-0,18$ & $-0,13$ & 0,45 & 0,05 & 0,04 & 0,09 & 0,02 & 0,12 & 0,13 & 0,14 & 0,02
\end{tabular}




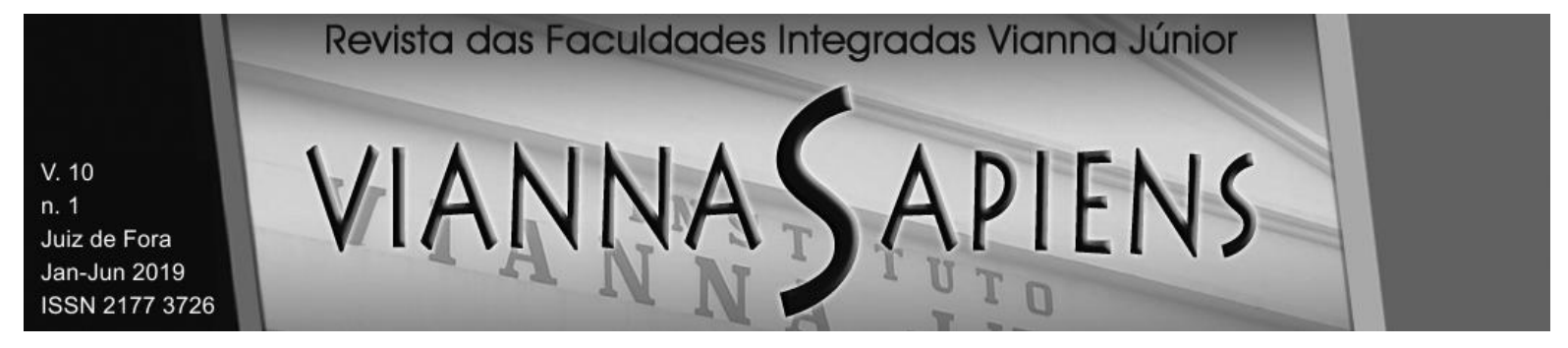

\begin{tabular}{|c|c|c|c|c|c|c|c|c|c|c|c|c|}
\hline LVGI & & 1,00 & 1,00 & 0,53 & 1,09 & 1,20 & 1,03 & 1,19 & 1,17 & 1,18 & 1,18 & 0,98 \\
\hline M-score & & $-1,31$ & $-3,10$ & 3,00 & $-1,94$ & $-2,25$ & $-2,76$ & $-2,91$ & $-2,69$ & $-6,10$ & $-1,51$ & $-2,54$ \\
\hline Alfa & & & 0,44 & 0,22 & 0,57 & ' & 0,40 & $-0,69$ & $-0,11$ & $-0,36$ & $-0,39$ & 0,01 \\
\hline Beta & & I & 0,28 & 0,18 & 0,06 & 0,14 & $-0,07$ & $-0,11$ & 0,00 & $-0,05$ & $-0,04$ & $-0,02$ \\
\hline Ibovespa & $33 \%$ & $44 \%$ & $-41 \%$ & $83 \%$ & $1 \%$ & $-18 \%$ & $7 \%$ & $-15 \%$ & $-3 \%$ & $-13 \%$ & $39 \%$ & $27 \%$ \\
\hline Empresa & & I & $-75 \%$ & $-13 \%:$ & $-8 \%$ & $-22 \%$ & $32 \%$ & $-51 \%$ & $-1 \%$ & $-29 \%$ & $-34 \%$ & $10 \%$ \\
\hline
\end{tabular}

A CEEE apresentou dois anos consecutivos, 2009 e 2010, do Índice Beneish M-Score indicativo de gerenciamento. Nesses, o índice de qualidade de ativos e o índice de vendas diárias e recebíves ficaram nos maiores níveis da série. Desta forma, a um mesmo custo, teria mais geração de receita e a qualidade de seus ativos estaria melhor. Beneish (1999) discorre que empresas em dificuldade normalmente manipulam estes índices para superestimá-los. O comportamento de suas ações em relação ao lbovespa apresentou um risco não correlacionado ao de mercado.

Há outros dois anos indicativos de gerenciamento, totalizando quatro anos de Beneish M-Score indicativo de fraude. Ainda, os retornos demonstraram que a empresa não se encontra em uma situação sustentável e sua situação não deveria atrair o investidor.

\section{Centrais Elétricas de Santa Catarina (Celesc)}

Tabela 7 - Índices Beneish M-Score, Alfa e Beta da Celesc

\begin{tabular}{lc|c|c|c|c|c|c|c|c|c|c|c}
\hline CELESC & 2006 & 2007 & 2008 & 2009 & 2010 & 2011 & 2012 & 2013 & 2014 & 2015 & 2016 & 2017 \\
\hline DSRI & 0,54 & 0,39 & 1,22 & 0,69 & 0,98 & 0,82 & 0,56 & 1,09 & 0,85 & 0,96 & 1,08 & 0,86 \\
GMI & 0,66 & 0,78 & 0,84 & 0,79 & 0,88 & 1,36 & 0,44 & 1,72 & 0,97 & 0,43 & 1,21 & 1,44 \\
AQI & 1,32 & 0,41 & 1,18 & 0,69 & 1,17 & 0,76 & 0,72 & 1,02 & 0,97 & 1,15 & 1,04 & 0,00 \\
SGI & 0,75 & 0,97 & 1,11 & 1,04 & 1,10 & 1,04 & 1,08 & 1,07 & 1,28 & 1,10 & 0,89 & 1,16 \\
DEPI & 1,61 & 0,69 & 1,12 & 0,91 & 1,13 & 0,87 & 1,17 & 1,11 & 0,95 & 1,24 & 0,98 & 1,05 \\
SGAI & 1,29 & 0,13 & 2,23 & 0,13 & 16,17 & 1,22 & 0,63 & 0,69 & 2,46 & 0,22 & 0,12 & 4,22 \\
TATA & $-0,03$ & $-0,29$ & $-0,03$ & $-0,21$ & $-0,03$ & $-0,06$ & 0,05 & $-0,11$ & 0,18 & $-0,23$ & $-0,35$ & $-0,14$ \\
LVGI & 0,34 & 0,76 & 0,99 & 0,86 & 0,32 & 0,85 & 0,16 & 4,30 & 1,90 & 0,33 & 0,29 & 2,61 \\
\hline M-score & $-3,10$ & $-4,59$ & $-2,54$ & $-3,75$ & $-4,89$ & $-2,82$ & $-2,62$ & $-3,46$ & $-2,09$ & $-3,35$ & $-3,65$ & $-4,34$ \\
\hline
\end{tabular}




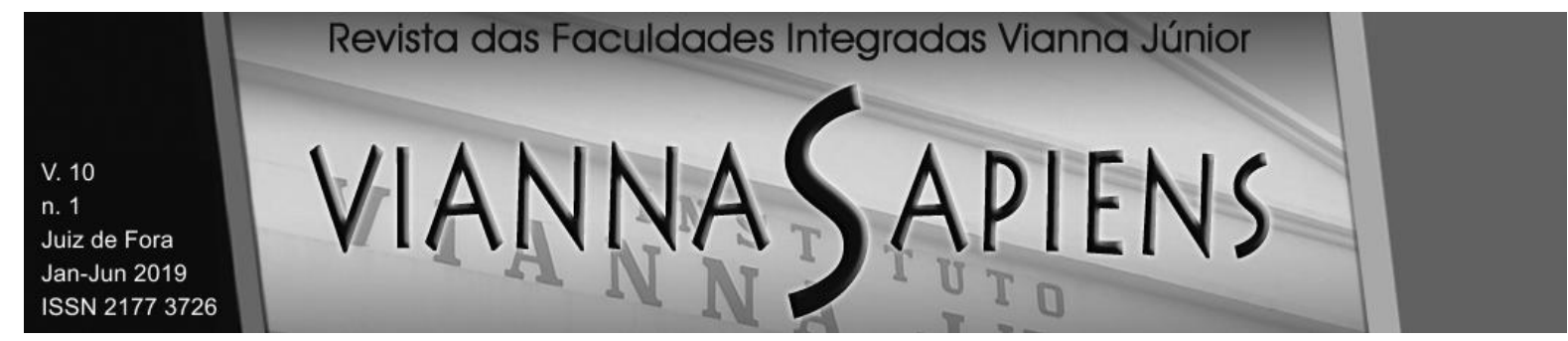

\begin{tabular}{ll:l:l:c:c:c:c:c:c:c:c:c} 
Alfa & 0,00 & $-0,05$ & 0,13 & $-0,17$ & 0,10 & 0,01 & $-0,26$ & $-0,35$ & $-0,17$ & $-0,01$ & 0,29 & 0,45 \\
\hline Beta & 0,79 & 0,89 & 0,62 & 0,29 & 0,29 & 0,47 & 0,07 & 0,31 & 0,21 & 0,70 & 0,43 & 0,45 \\
\hline Ibovespa & $33 \%$ & $44 \%$ & $-41 \%$ & $83 \%$ & $1 \%$ & $-18 \%$ & $7 \%$ & $-15 \%$ & $-3 \%$ & $-13 \%$ & $39 \%$ & $27 \%$ \\
\hline Empresa & $28 \%$ & $31 \%$ & $-16 \%$ & $7 \%$ & $17 \%$ & $-4 \%$ & $-20 \%$ & $-32 \%$ & $-12 \%$ & $-17 \%$ & $72 \%$ & $71 \%$ \\
\hline
\end{tabular}

Fonte: Autores

A Celesc apresentou apenas um ano de indício de gerenciamento. Ao longo de todos os anos, o índice de ativos totais (TATA), ficou negativo ou atinge, no máximo, 0,05 em 2012. Em 2014, reverte de sinal e atinge 0,18. Sem deixar de considerar os demais fatores, como seu multiplicador no Índice Beneish M-Score é relevante, seu impacto acabou sendo maior. Nesse indicador, é refletida a variação do capital de giro, em relação ao caixa, gastos, impostos a pagar e depreciação. $O$ comportamento de suas ações em relação ao lbovespa refletiu um risco não correlacionado ou inferior ao de mercado, mas com aumento considerável no ano seguinte ao da detecção de gerenciamento pelo indicador.

\section{Centrais Elétricas de Minas Gerais SA (Cemig)}

Tabela 8 - Índices Beneish M-Score, Alfa e Beta da Cemig

\begin{tabular}{lc|c|c|c|c|c|c|c|c|c|c|c}
\hline CEMIG & 2006 & 2007 & 2008 & 2009 & 2010 & 2011 & 2012 & 2013 & 2014 & 2015 & 2016 & 2017 \\
\hline DSRI & 0,64 & 0,88 & 0,92 & 0,92 & 1,31 & 0,88 & 1,58 & 0,66 & 0,54 & 1,67 & 0,96 & 0,79 \\
GMI & 1,00 & 1,36 & 0,98 & 0,98 & 0,97 & 1,04 & 0,89 & 0,99 & 1,06 & 0,75 & 0,89 & 0,84 \\
AQI & 0,80 & 0,89 & 0,90 & 0,91 & 1,11 & 1,04 & 0,34 & 1,19 & 1,51 & 1,23 & 1,02 & 0,74 \\
SGI & 1,18 & 1,06 & 1,06 & 1,07 & 1,10 & 1,23 & 1,17 & 0,79 & 1,34 & 1,09 & 0,88 & 1,16 \\
DEPI & 1,02 & 1,11 & 0,84 & 0,95 & 0,99 & 1,00 & 0,96 & 0,87 & 0,95 & 0,95 & 1,06 & 0,94 \\
SGAI & $-0,06$ & $-8,59$ & 1,36 & 0,24 & 0,00 & 0,00 & 0,00 & 0,00 & 0,00 & 0,00 & 0,00 & 0,00 \\
TATA & 0,20 & 0,19 & 0,19 & 0,17 & 0,19 & 0,19 & 0,26 & 0,22 & 0,25 & 0,15 & 0,02 & 0,06 \\
LVGI & 0,74 & 0,75 & 0,92 & 0,94 & 1,11 & 1,27 & 1,56 & 0,36 & 1,67 & 1,16 & 0,79 & 0,60 \\
\hline M-score & $-1,55$ & 0,26 & $-1,71$ & $-1,57$ & $-1,06$ & $-1,35$ & $-0,93$ & $-1,49$ & $-1,25$ & $-0,98$ & $-2,31$ & $-2,14$ \\
\hline Alfa & $-0,06$ & $-0,36$ & 0,25 & 0,04 & $-0,02$ & 0,36 & 0,02 & 0,15 & 0,20 & $-0,59$ & $-0,04$ & $-0,31$ \\
\hline Beta & 1,02 & 0,96 & 0,47 & 0,28 & 0,38 & 0,43 & 0,15 & 0,75 & 0,85 & 0,77 & 1,76 & 1,60 \\
\hline Ibovespa & $33 \%$ & $44 \%$ & $-41 \%$ & $83 \%$ & $1 \%$ & $-18 \%$ & $7 \%$ & $-15 \%$ & $-3 \%$ & $-13 \%$ & $39 \%$ & $27 \%$ \\
\hline Empresa & $23 \%$ & $-3 \%$ & $5 \%$ & $31 \%$ & $2 \%$ & $37 \%$ & $3 \%$ & $0 \%$ & $19 \%$ & $-52 \%$ & $42 \%$ & $-6 \%$ \\
\hline F
\end{tabular}




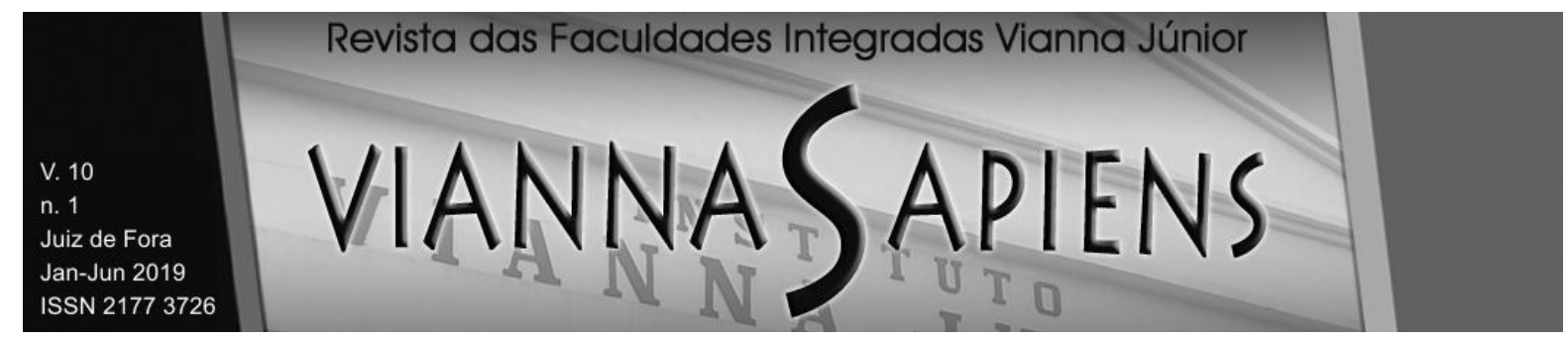

A Cemig apresentou indício de gerenciamento pelo Índice Beneish M-Score em todos os anos, à exceção de 2016. O risco em relação ao índice de mercado manteve-se inferior de 2007 até ano de 2015, em 2016 houve um incremento muito significativo no risco, superando o de mercado. Em relação ao Alfa, não apresentou tendência definida, com média de -0,03 e desvio de 0,26.

Para o investidor mais atento, a reincidência de indicativo de gerenciamento de resultados, no caso da Cemig, se manter ausente de investir parece ser o mais coerente: de 2006 até 2017 a Empresa valorizou-se 102\%, enquanto o Ibovespa obteve $142 \%$.

De acordo com os Resultados da Companhia, ao longo de 2006 a 2015 a Cemig fez quase 30 aquisições e participou dos principais leilões de geração e transmissão no país (CEMIG, 2019). Ainda, a companhia afirma em seu Relatório que, diante de um cenário de retração econômica que trouxe o desemprego, associado à crise hidrológica e o aumento das tarifas que estavam represadas, a Cemig tem sofrido com o crescimento no estoque da dívida acima da média.

\section{Companhia Energética de São Paulo (CESP)}

Tabela 9 - Índices Beneish M-Score, Alfa e Beta da Cesp

\begin{tabular}{|c|c|c|c|c|c|c|c|c|c|c|c|c|}
\hline CESP & 2006 & 2007 & 2008 & 2009 & 2010 & 2011 & 2012 & 2013 & 2014 & 2015 & 2016 & 2017 \\
\hline DSRI & 95 & 0,91 & 1,20 & 0,91 & 1,05 & 0,93 & 0,48 & 2,73 & 0,94 & 1,82 & 1,65 & 1,22 \\
\hline GMI & 1,10 & 1,26 & 0,74 & 1,36 & 0,82 & 0,98 & 0,84 & 1,53 & 1,13 & 0,70 & 1,02 & 0,37 \\
\hline AQI & 1,03 & 0,91 & 1,68 & 1,01 & 0,99 & 0,95 & 0,48 & 4,62 & 1,27 & 1,39 & 1,02 & 0,00 \\
\hline SGI & 1,12 & 1,06 & 1,14 & 1,07 & 1,10 & 1,02 & 1,13 & 1,16 & 1,24 & 0,61 & 0,57 & 0,88 \\
\hline DEP & 0,80 & 2,22 & 1,19 & 1,04 & 1,37 & 1,03 & 1,03 & 1,19 & 1,21 & 0,84 & 0,70 & 1,09 \\
\hline SGA & 0,70 & 1,58 & 0,47 & 1,04 & 3,58 & 0,69 & 0,72 & 4,28 & 0,87 & 0,69 & 0,98 & 0,77 \\
\hline TATA & $-0,02$ & $-0,04$ & 0,07 & $-0,04$ & $-0,08$ & $-0,09$ & $-0,12$ & $-0,19$ & $-0,25$ & $-0,14$ & $-0,07$ & $-0,03$ \\
\hline LVGI & 0,76 & 0,98 & 1,13 & 0,89 & 0,93 & 1,00 & 0,93 & 0,93 & 1,07 & 0,95 & 0,96 & 0,97 \\
\hline M-score & $-2,34$ & $-2,54$ & $-1,63$ & $-2,48$ & $-3,19$ & $-2,92$ & $-3,62$ & $-0,41$ & $-3,28$ & $-2,68$ & $-2,58$ & $-3,21$ \\
\hline Alfa & & : 0,28 & $-0,53$ & 0,29 & 0,14 & 0,31 & $-0,46$ & 0,35 & 0,30 & $:-0,33$ & $-0,24$ & $-0,19$ \\
\hline Beta & & 0,83 & 0,68 & 0,23 & 0,79 & 0,56 & ד, & 10,77 & 0,75 & 10,72 & 0,91 & 0,97 \\
\hline Ibovespa & $33 \%$ & $44 \%$ & $-41 \%$ & $83 \%$ & $1 \%$ & $1-18 \%$ & $17 \%$ & $1-15 \%$ & $1-3 \%$ & $1-13 \%$ & $39 \%$ & $27 \%$ \\
\hline Empresa & & :74\% & $:-65 \%$ & $62 \%$ & $14 \%$ & $25 \%$ & $:-39 \%$ & $24 \%$ & $34 \%$ & $1-37 \%$ & $4 \%$ & $1 \%$ \\
\hline
\end{tabular}




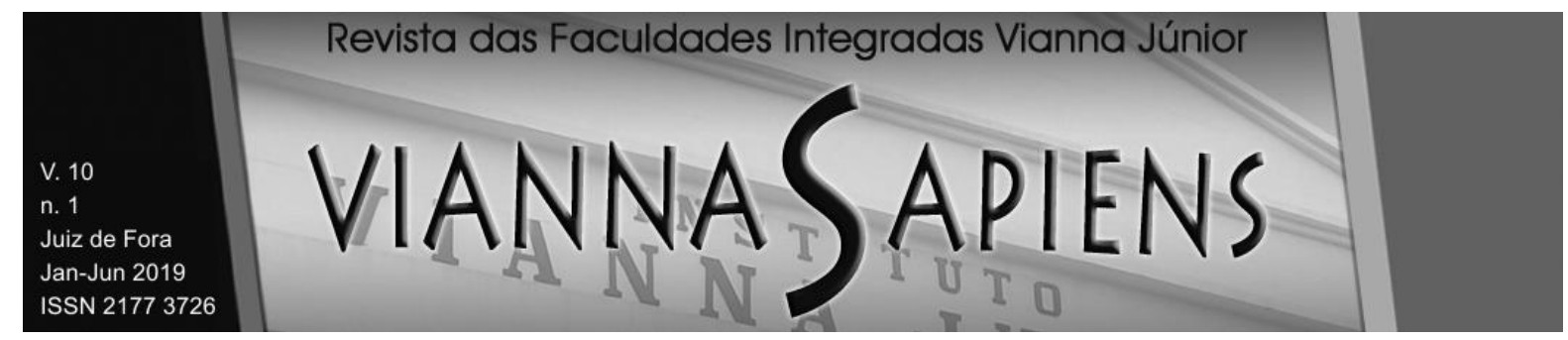

A CESP apresentou em 2008 e 2013 indícios de gerenciamento pelo MScore. Em 2008, não há como desconsiderar que o índice de ativos totais (TATA) reverte de sinal. Como seu multiplicador no Índice Beneish M-Score é relevante, nota-se que o capital de giro aumentou muito mais que o caixa, os gastos, impostos a pagar e depreciação. O resultado de 2008 foi impactado negativamente pelo reconhecimento das provisões para o prejuízo dos ativos fixos da fábrica de Porto Primavera (CESP, 2019).

De acordo com o Relatório da Administração, CESP (2019) em 2013, houve um aumento significativo na proporção de custos administrativos em relação às vendas. Para melhor análise, deve-se lembrar que em maio de 2013 foi publicada a lei que concedeu desconto na conta de luz.

O comportamento de suas ações em relação ao lbovespa refletiu um risco inferior ao de mercado (Beta menor que1) e por vezes não correlacionado. O Alfa não apresentou tendência definida, com média de -0,01 e desvio de 0,33.

\section{Companhia de Saneamento de Minas Gerais (Copasa)}

Tabela 10 - Índices Beneish M-Score, Alfa e Beta da Copasa

\begin{tabular}{|c|c|c|c|c|c|c|c|c|c|c|c|c|}
\hline COPASA & 2006 & 2007 & 2008 & 2009 & 2010 & 2011 & 2012 & 2013 & 2014 & 2015 & 2016 & 2017 \\
\hline DSRI & 0,99 & 1,22 & 1,14 & 1,04 & 1,04 & 1,23 & 0,94 & 1,05 & 0,88 & 1,17 & 1,00 & 0,99 \\
\hline GMI & 1,02 & 0,95 & 1,01 & 0,68 & 1,04 & 1,09 & 0,95 & 0,97 & 0,91 & 0,87 & 1,29 & 1,11 \\
\hline AQI & 1,36 & 0,73 & 1,29 & 1,88 & 0,86 & 1,22 & 0,84 & 1,05 & 0,89 & 0,99 & 0,97 & 0,00 \\
\hline SGI & 1,14 & 1,11 & 1,10 & 1,59 & 0,99 & 1,00 & 1,09 & 1,06 & 1,11 & 0,93 & 1,05 & 1,07 \\
\hline DEPI & 0,86 & 0,93 & 0,95 & 1,02 & 0,89 & 1,04 & 1,14 & 1,07 & 1,04 & 1,07 & 1,10 & 0,96 \\
\hline SGAI & 0,93 & 0,85 & 0,92 & 0,68 & 0,79 & 2,33 & 0,95 & 1,07 & 1,07 & 1,13 & 0,86 & 1,10 \\
\hline TATA & $-0,06$ & $-0,07$ & $-0,08$ & $-0,04$ & $-0,03$ & $-0,07$ & $-0,07$ & $-0,08$ & $-0,08$ & $-0,10$ & $-0,10$ & $-0,10$ \\
\hline LVGI & 0,79 & 1,15 & 1,08 & 1,09 & 0,93 & 1,07 & 0,98 & 0,97 & 1,04 & 1,06 & 0,94 & 0,92 \\
\hline M-score & $-2,42$ & $-2,66$ & $-2,54$ & $-1,89$ & $-2,60$ & $-2,70$ & $-2,83$ & $-2,73$ & $-2,99$ & $-2,95$ & $-2,70$ & $-3,23$ \\
\hline Alfa & & $-0,04$ & $-0,15$ & 0,32 & $-0,10$ & 0,26 & 0,27 & $-0,02$ & $-0,34$ & $-0,30$ & 0,97 & 0,09 \\
\hline Beta & & 0,91 & 0,63 & 0,56 & 0,48 & 0,47 & 0,45 & 0,64 & 0,57 & 0,60 & 1,08 & 0,82 \\
\hline Ibovespa & $33 \%$ & $44 \%$ & $-41 \%$ & $83 \%$ & $1 \%$ & $-18 \%$ & $7 \%$ & $-15 \%$ & $-3 \%$ & $-13 \%$ & $39 \%$ & $27 \%$ \\
\hline Empros? & & $27 \%$ & $-37 \%$ & $88 \%$ & $-7 \%$ & $23 \%$ & $35 \%$ & $-12 \%$ & $-30 \%$ & $-38 \%$ & $145 \%$ & $25 \%$ \\
\hline
\end{tabular}




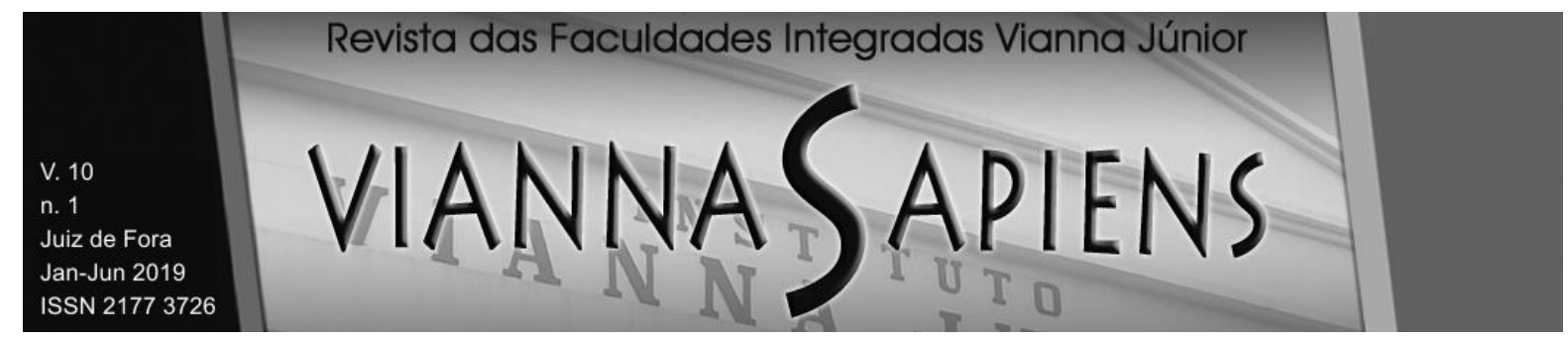

A Copasa apresentou o índice Beneish M-Score indicativo de gerenciamento de resultados apenas em 2009. Aumentou o índice de qualidade de ativo, que, para Beneish (1999), é a relação entre os ativos não circulantes (excluindo-se também o imobilizado) e o ativo total, e mede a proporção do total de ativos para os quais os benefícios futuros são potencialmente menos certos. Destaca-se que, em 2009, a empresa realizou a adoção do IFRS, o que impactou receitas e despesas sem reflexo no caixa (COPASA, 2019). O comportamento de suas ações em relação ao lbovespa refletiu um risco inferior ao de mercado na maior parte da série. O Alfa não apresentou tendência definida, com média de 0,12 e desvio de 0,18.

\section{Companhia Paranaense de Energia (Copel)}

Tabela 11 - Índices Beneish M-Score, Alfa e Beta da Copasa

\begin{tabular}{ll|l|l|l|l|l|l|l|l|l|l|l}
\hline COPEL & 2006 & 2007 & 2008 & 2009 & 2010 & 2011 & 2012 & 2013 & 2014 & 2015 & 2016 & 2017 \\
\hline DSRI & 0,89 & 1,03 & 1,12 & 0,98 & 0,96 & 1,01 & 0,88 & 0,85 & 0,68 & 1,02 & 1,33 & 0,87 \\
GMI & 2,67 & 0,94 & 0,86 & 0,91 & 0,85 & 1,07 & 0,77 & 1,02 & 0,85 & 1,01 & 1,10 & 1,09 \\
AQI & 0,48 & 1,11 & 1,13 & 0,90 & 1,05 & 0,99 & 0,99 & 1,17 & 0,95 & 0,96 & 1,22 & 0,76 \\
SGI & 1,11 & 1,01 & 1,01 & 1,03 & 1,23 & 1,13 & 1,10 & 1,08 & 1,52 & 1,06 & 0,89 & 1,07 \\
DEPI & 0,94 & 1,04 & 0,92 & 0,94 & 1,05 & 0,98 & 0,95 & 1,00 & 0,96 & 0,99 & 1,05 & 0,97 \\
SGAI & 0,00 & 0,82 & 0,79 & 0,91 & 1,55 & 1,13 & 0,52 & 1,47 & 0,76 & 0,94 & 0,92 & 1,06 \\
TATA & $-0,07$ & $-0,08$ & $-0,05$ & $-0,06$ & $-0,08$ & $-0,09$ & $-0,09$ & $-0,10$ & $-0,12$ & $-0,07$ & $-0,18$ & $-0,06$ \\
LVGI & 1,19 & 0,71 & 0,87 & 0,74 & 0,99 & 0,89 & 0,98 & 1,13 & 1,17 & 1,08 & 0,89 & 1,08 \\
\hline M-score & $-2,04$ & $-2,68$ & $-2,55$ & $-2,73$ & $-2,85$ & $-2,75$ & $-2,97$ & $-3,07$ & $-3,01$ & $-2,78$ & $-2,94$ & $-2,93$ \\
\hline Alfa & 0,12 & $-0,19$ & 0,27 & 0,08 & 0,08 & 0,00 & $-0,23$ & 0,24 & 0,28 & $-0,22$ & $-0,20$ & $-0,24$ \\
\hline Beta & 0,77 & 0,84 & 0,60 & 0,61 & 0,30 & 0,39 & 0,41 & 0,91 & 0,97 & 0,80 & 1,34 & 1,04 \\
\hline Ibovespa & $33 \%$ & $44 \%$ & $-41 \%$ & $83 \%$ & $1 \%$ & $-18 \%$ & $7 \%$ & $-15 \%$ & $-3 \%$ & $-13 \%$ & $39 \%$ & $27 \%$ \\
\hline Empresa & $42 \%$ & $12 \%$ & $-7 \%$ & $64 \%$ & $14 \%$ & $-2 \%$ & $-17 \%$ & $3 \%$ & $26 \%$ & $-30 \%$ & $18 \%$ & $-2 \%$ \\
\hline
\end{tabular}

Fonte: Autores

A Copel apresentou o índice Beneish M-Score indicativo de gerenciamento de resultados apenas em 2006. Como destaque é possível perceber o índice de margem bruta, que, para Beneish (1999), se estiver acima de 1 significa que a empresa piorou sua margem e, portanto, estaria mais propensa a gerenciar seus 


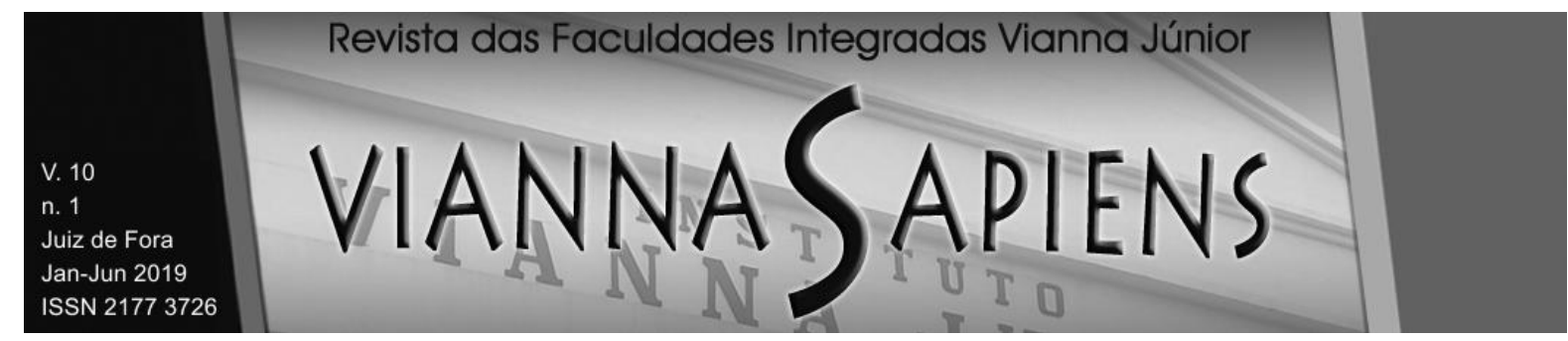

resultados, e o de vendas. A empresa destacou que passou a poder oferecer seus serviços a mais clientes por autorização do órgão regulador.

No ano seguinte, houve deterioração de valor da ação (Alfa negativo) e elevação de seu risco (Beta). Nos demais anos, o Beta reduziu, portanto, as ações da empresa apresentaram uma correlação menor com o índice de mercado, retornando à tendência de alta, posteriormente.

O Alfa não apresentou tendência definida, com média de 0,00 e desvio de 0,20 .

\section{Centrais Elétricas Brasileiras S.A (Eletrobras)}

Tabela 12 - Índices Beneish M-Score, Alfa e Beta da Eletrobras

\begin{tabular}{|c|c|c|c|c|c|c|c|c|c|c|c|c|}
\hline $\begin{array}{l}\text { ELETRO- } \\
\text { BRAS } \\
\end{array}$ & 2006 & 2007 & 2008 & 2009 & 2010 & 2011 & 2012 & 2013 & 2014 & 2015 & 2016 & 2017 \\
\hline DSRI & 1,11 & 0,80 & 0,89 & 1,01 & 0,67 & 0,98 & 0,82 & 1,21 & 1,08 & 1,06 & 0,53 & 1,38 \\
\hline GMI & 0,95 & 1,20 & 0,96 & 1,06 & 1,02 & 1,00 & 1,00 & 0,98 & 0,54 & 1,04 & 1,53 & 0,81 \\
\hline AQI & 0,97 & 1,00 & 0,97 & 0,95 & 1,01 & 1,01 & 1,03 & 1,02 & 1,02 & 0,98 & 1,01 & 0,96 \\
\hline SGI & 0,95 & 1,14 & 1,34 & 0,87 & 1,14 & 1,11 & 1,20 & 0,71 & 1,07 & 1,08 & 1,86 & 0,62 \\
\hline DEPI & 3,20 & 1,21 & 1,08 & 0,77 & 0,28 & 0,84 & 1,33 & 0,95 & 0,91 & 0,80 & 0,74 & 0,89 \\
\hline SGAI & 0,95 & 1,06 & 0,95 & 0,99 & 0,34 & 1,00 & 1,00 & 2,79 & 0,51 & 2,13 & 0,74 & 0,99 \\
\hline TATA & $-0,01$ & $-0,02$ & 0,04 & $-0,02$ & 0,00 & 0,02 & 0,06 & 0,06 & 0,03 & 0,15 & 0,02 & 0,01 \\
\hline LVGI & 1,00 & 1,03 & 1,27 & 1,34 & 1,13 & 0,93 & 1,10 & 1,05 & 1,15 & 1,35 & 1,11 & 1,05 \\
\hline M-score & $-2,26$ & $-2,51$ & $-2,21$ & $-2,79$ & $-2,67$ & $-2,28$ & $-2,15$ & $-2,60$ & $-2,44$ & $-1,99$ & $-1,77$ & $-2,55$ \\
\hline Alfa & 0,09 & 0,36 & 0,56 & 0,12 & $-0,10$ & $-0,04$ & $0,92 !$ & 0,51 & 0,18 & 0,27 & 1,08 & $-0,35$ \\
\hline Beta & 01 & 0,79 & 0,77 & 0,42 & 0,95 & 0,74 & 0,13 & 1180 & 1,48 & 1,32 & 1,20 & 2,10 \\
\hline lbov & $33 \%$ & $44 \%$ & $-41 \%$ & $83 \%$ & $1 \%$ & $-18 \%$ & $7 \%$ & $-15 \%$ & $-3 \%$ & $-13 \%$ & $39 \%$ & $27 \%$ \\
\hline sa & $35 \%$ & $-6 \%$ & $10 \%$ & $48 \%$ & $-13 \%$ & $-16 \%$ & $-61 \%$ & $1 \%$ & $4 \%$ & $-1 \%$ & $296 \%$ & $15 \%$ \\
\hline
\end{tabular}

A Eletrobras apresentou em 2008, 2012, 2015 e 2016 indicação de gerenciamento de resultados pelo modelo do Índice Beneish M-Score. O SGI seria um indicador que poderia estar impactando por seu coeficiente elevado e observações em 2008, 2012 e 2016. A métrica é uma medida do crescimento das vendas em um ano sobre a receita de vendas do ano anterior, e para Beneish 


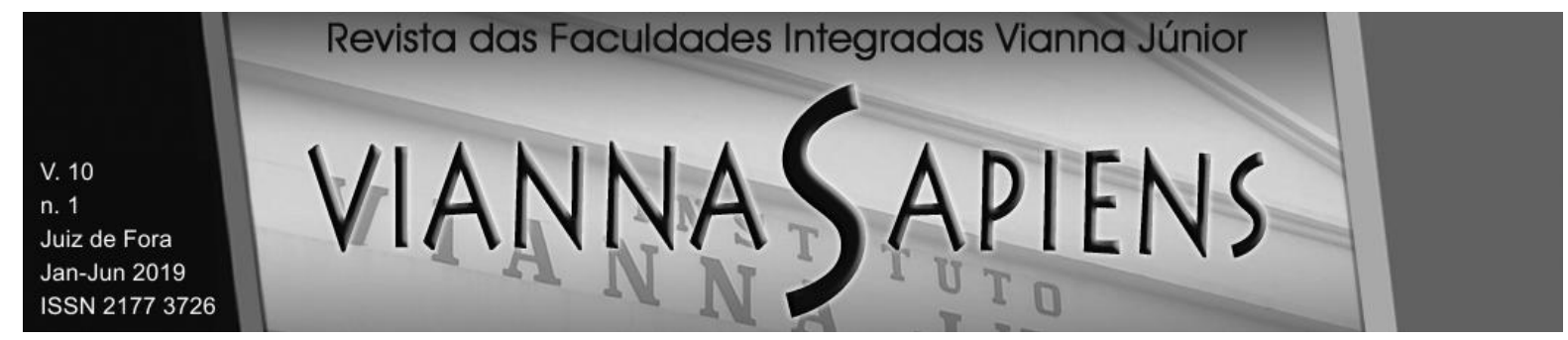

(1999), em períodos de alto crescimento, no primeiro sinal de uma desaceleração, elas podem ter maiores incentivos para gerenciar os ganhos.

Em 2008, o resultado financeiro da Eletrobrás foi muito impactado pelos recebíveis indexados principalmente à moeda norte-americana, que, com a desvalorização da moeda brasileira, fez o resultado ficar melhor. A moeda americana estava desvalorizando até então.

Em setembro de 2012, a Medida Provisória 579/12, convertida na Lei 12.783, estabeleceu a forma de prorrogação dos contratos de concessão da geração, transmissão e distribuição. A motivação pela modicidade tarifária e redução dos valores das contas de energia em todas as classes de consumo de energia do país (em média 18\% mais barata) levou o governo federal a propor o vencimento antecipado dos contratos de concessão, com a automática prorrogação dentro das condições estabelecidas e, como alternativa, a relicitação da concessão decorrido o prazo contratual original (renovação por 30anos).

A Eletrobrás apresentou, no resultado de 2015, prejuízo líquido atribuído aos controladores (Estado) influenciado por empréstimo compulsório e Impairments. Em 2016, houve reversão recuperando o prejuízo líquido atribuído aos controladores de $\mathrm{R} \$ 14.442$ milhões em 2015.

Após 2012, é possível detectar um movimento claro no Beta, cujo risco foi elevado comparativamente ao de mercado (Beta superior a 1).

O Alfa após os anos em que o modelo indica possível gerenciamento de resultados não apresentou tendência definida, com média de 0,09 e desvio de 0,42.

\section{Empresa Metropolitana Energias S.A (EMAE)}

Tabela 13 - Índices Beneish M-Score, Alfa e Beta da EMAE

\begin{tabular}{ll|l|l|l|l|l|l|l|l|l|l|l}
\hline EMAE & 2006 & 2007 & 2008 & 2009 & 2010 & 2011 & 2012 & 2013 & 2014 & 2015 & 2016 & 2017 \\
\hline DSRI & 1,29 & 1,08 & 1,75 & 1,64 & 1,11 & 0,86 & 1,07 & 0,85 & 1,86 & 0,92 & 0,96 & 1,06 \\
GMI & 5,10 & 0,77 & $-0,23$ & $-4,70$ & 1,05 & 1,04 & 0,28 & $-0,21$ & $-1,97$ & $-1,50$ & 1,24 & $-0,02$ \\
AQI & 0,95 & 1,09 & 3,28 & 1,05 & 0,97 & 1,00 & 1,17 & 0,90 & 1,79 & 1,04 & 0,95 & 0,96 \\
SGI & 0,65 & 0,80 & 2,61 & 0,64 & 0,89 & 1,15 & 1,06 & 1,11 & 0,78 & 1,13 & 1,04 & 1,00 \\
DEPI & 1,05 & 1,05 & 1,09 & 0,93 & 1,01 & 1,09 & 1,22 & 0,76 & 1,41 & 0,69 & 0,72 & 0,54
\end{tabular}




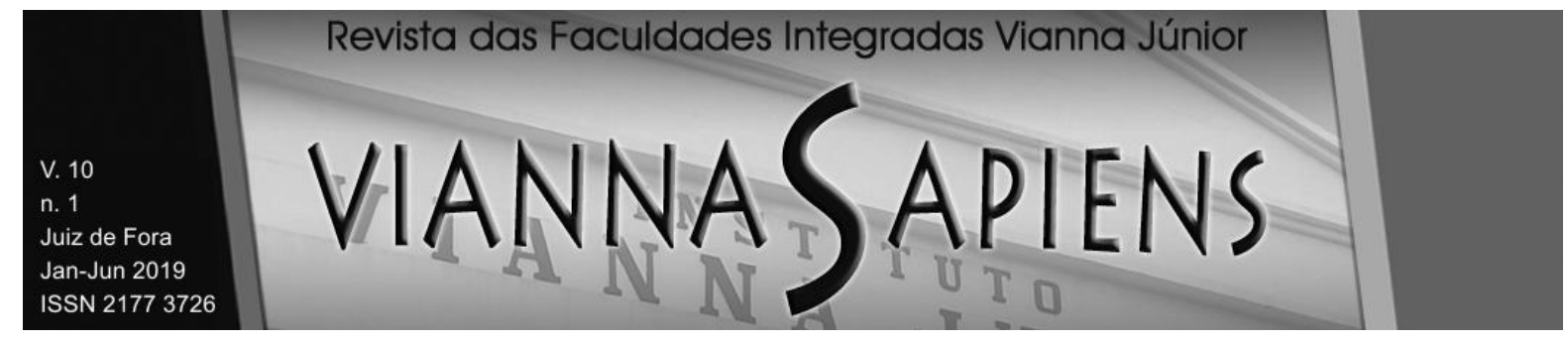

\begin{tabular}{ll|l|l|l|l|l|l|l|l|l|l|l} 
SGAI & 1,31 & 1,08 & 0,40 & 1,41 & 1,13 & 1,76 & 1,48 & 0,01 & 156,3 & 0,43 & 0,58 & 4,26 \\
TATA & $-0,04$ & $-0,02$ & $-0,07$ & $-0,13$ & $-0,11$ & $-0,11$ & $-0,05$ & $-0,12$ & $-0,13$ & $-0,11$ & $-0,12$ & $-0,05$ \\
LVGI & 1,06 & 1,18 & 1,03 & 1,04 & 0,99 & 1,13 & 1,23 & 0,75 & 1,06 & 0,77 & 1,26 & 0,97 \\
\hline M-score & $-0,64$ & $-2,81$ & $-0,31$ & $-5,92$ & $-3,01$ & $-3,13$ & $-3,02$ & $-3,66$ & $-3,73$ & $-4,12$ & $-2,97$ & $-3,82$ \\
\hline Alfa & 0,00 & 0,51 & $-0,60$ & 0,77 & $-0,58$ & $-0,22$ & 0,07 & $-0,43$ & $-0,42$ & 0,13 & 0,56 & 0,02 \\
\hline Beta & 0,66 & 0,83 & $-0,16$ & 0,06 & 0,59 & $-0,19$ & $-0,33$ & $-0,35$ & 0,31 & $-0,13$ & 0,45 & 0,13 \\
\hline Ibovespa & $33 \%$ & $44 \%$ & $-41 \%$ & $83 \%$ & $1 \%$ & $-18 \%$ & $7 \%$ & $-15 \%$ & $-3 \%$ & $-13 \%$ & $39 \%$ & $27 \%$ \\
\hline \multicolumn{2}{l}{ Empresa } & $18 \%$ & $108 \%$ & $-46 \%$ & $115 \%$ & $-44 \%$ & $-11 \%$ & $8 \%$ & $-22 \%$ & $-33 \%$ & $12 \%$ & $109 \%$ \\
\hline Fonte: Autores
\end{tabular}

A EMAE apresentou dois anos, 2006 e 2008, de Índice Beneish M-Score indicativo de gerenciamento de resultados. Em 2006, destaque-se o GMI, índice de margem bruta, que, quanto mais alto, mais a empresa piorou sua margem e, portanto, estaria mais propensa a gerenciar. No ano de 2008 apresentou índice de qualidade de ativos e índice de vendas diárias e recebíveis nos maiores níveis da série. O movimento no Beta e Alfa de suas ações não apresentaram tendência definida, com o excesso de retorno médio de -0,02 e desvio de 0,44.

\section{Petróleo Brasileiro S.A (Petrobras)}

Tabela 14 - Índices Beneish M-Score, Alfa e Beta da Petrobras

\begin{tabular}{lc|c|c|c|c|c|c|c|c|c|c|c}
\hline $\begin{array}{l}\text { PETRO- } \\
\text { BRAS }\end{array}$ & 2006 & 2007 & 2008 & 2009 & 2010 & 2011 & 2012 & 2013 & 2014 & 2015 & 2016 & 2017 \\
\hline DSRI & 1,17 & 1,29 & 1,29 & 0,79 & 0,72 & 0,67 & 0,79 & 0,78 & 1,09 & 1,42 & 1,24 & 1,08 \\
GMI & 0,99 & 0,99 & 0,90 & 1,09 & 0,89 & 0,84 & 0,70 & 0,94 & 1,07 & 1,33 & 1,02 & 1,01 \\
AQI & 1,05 & 1,12 & 1,02 & 0,76 & 0,65 & 0,83 & 1,07 & 0,88 & 1,06 & 1,28 & 1,04 & 1,13 \\
SGI & 1,13 & 1,06 & 1,28 & 0,83 & 1,17 & 1,17 & 1,18 & 1,09 & 1,14 & 0,93 & 0,89 & 1,02 \\
DEPI & 1,12 & 0,91 & 0,92 & 1,01 & 0,60 & 1,05 & 1,04 & 1,11 & 1,02 & 1,22 & 1,35 & 0,86 \\
SGAI & 1,00 & 1,35 & 0,35 & 2,35 & 0,74 & 1,10 & 1,00 & 0,78 & 3,26 & 1,14 & 0,72 & 0,74 \\
TATA & $-0,05$ & $-0,09$ & $-0,06$ & 0,02 & 0,04 & 0,00 & $-0,03$ & $-0,01$ & $-0,03$ & $-0,02$ & $-0,03$ & $-0,05$ \\
LVGI & 0,94 & 1,01 & 1,19 & 0,89 & 0,71 & 0,97 & 1,18 & 1,15 & 1,14 & 1,23 & 1,00 & 1,00 \\
\hline M-score & $-2,40$ & $-2,59$ & $-2,27$ & $-2,97$ & $-2,49$ & $-2,81$ & $-2,84$ & $-2,75$ & $-2,79$ & $-2,04$ & $-2,39$ & $-2,51$ \\
\hline Alfa & 0,06 & 0,28 & 0,02 & $-0,07$ & $-0,23$ & 0,02 & $-0,12$ & 0,10 & $-0,23$ & 0,11 & 0,25 & $-0,17$ \\
\hline Beta & 1,23 & 1,00 & 1,10 & 0,94 & 1,21 & 1,02 & 0,87 & 1,02 & 1,73 & 1,99 & 2,22 & 1,28 \\
\hline Ibovespa & $33 \%$ & $44 \%$ & $-41 \%$ & $83 \%$ & $1 \%$ & $-18 \%$ & $7 \%$ & $-15 \%$ & $-3 \%$ & $-13 \%$ & $39 \%$ & $27 \%$ \\
\hline
\end{tabular}




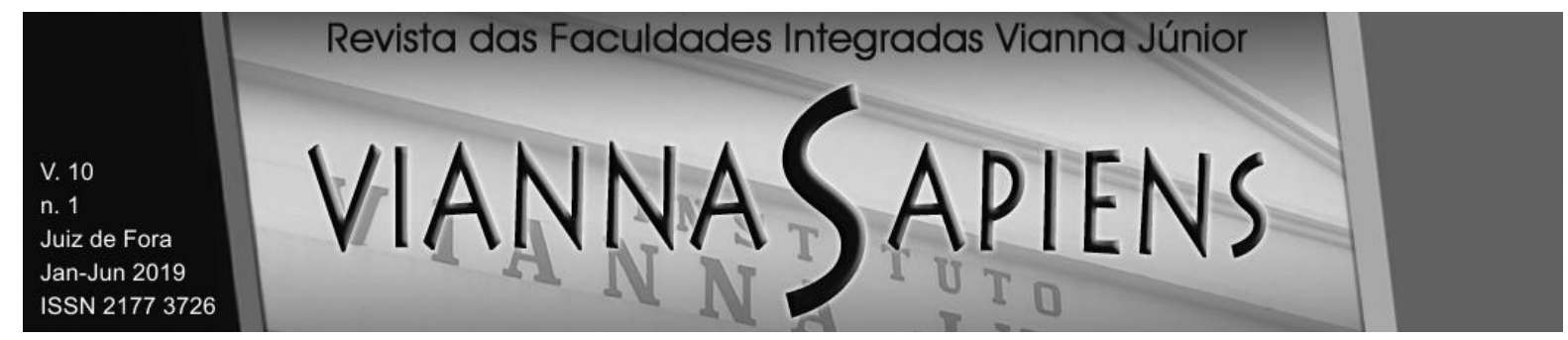

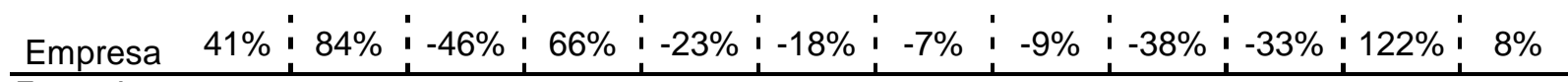
Fonte: Autores

A Petrobras apresentou apenas no ano de 2015 indicador positivo. Seu índice de DSRI, GMI, AQI e LEVI foram os mais elevados da série analisada. Assim, o índice de vendas diárias e recebíveis e o índice de qualidade dos ativos melhoraram, enquanto a margem bruta piorou com elevação da alavancagem. Seu risco em relação ao mercado atinge valores máximos em 2015 e 2016, e, no período analisado, seu risco é, na maioria das vezes, superior ao de mercado. Entretanto, o Alfa melhora nestes anos. O Alfa não apresenta tendência definida, com média de 0,00 e desvio de 0,17 .

Em sua demonstração de resultados de 2015, esclarece sobre a nota explicativa 3 às demonstrações contábeis, que descreve os reflexos da "Operação Lava Jato" sobre a companhia, abrangendo a baixa contábil, referentes a gastos adicionais capitalizados indevidamente na aquisição de ativos imobilizados, as providências que estão sendo adotadas em relação ao tema, a investigação que vem sendo conduzida pela U.S. Securities and Exchange Commission - SEC; e o Inquérito Civil instaurado pelo Ministério Público do Estado de São Paulo para apuração de potenciais danos causados a investidores no mercado de valores mobiliários no Brasil (PETROBRAS SA, 2018).

\section{Companhia de Saneamento Básico do Estado de São Paulo (Sabesp)}

Tabela 15 - Índices Beneish M-Score, Alfa e Beta da Sabesp

\begin{tabular}{ll|l|l|l|l|l|l|l|l|l|l|l}
\hline SABESP & 2006 & 2007 & 2008 & 2009 & 2010 & 2011 & 2012 & 2013 & 2014 & 2015 & 2016 & 2017 \\
\hline DSRI & 0,92 & 1,00 & 1,00 & 0,93 & 0,47 & 0,98 & 0,86 & 1,00 & 0,91 & 1,39 & 0,90 & 0,95 \\
GMI & 1,02 & 1,04 & 1,01 & 0,98 & 0,81 & 0,90 & 1,01 & 1,00 & 0,80 & 0,92 & 1,22 & 1,11 \\
AQI & 1,36 & 1,02 & 1,15 & 1,14 & 0,25 & 0,90 & 0,91 & 0,94 & 0,81 & 1,54 & 0,88 & 0,84 \\
SGI & 1,12 & 1,08 & 1,06 & 1,06 & 1,37 & 1,08 & 1,08 & 1,05 & 0,99 & 1,04 & 1,20 & 1,04 \\
DEPI & 1,09 & 0,96 & 0,94 & 0,88 & 0,82 & 1,27 & 0,88 & 1,08 & 1,05 & 0,98 & 0,98 & 1,06 \\
SGAI & 1,14 & 1,00 & 1,02 & 1,07 & 0,68 & 1,06 & 0,86 & 0,89 & 1,24 & 0,23 & 3,38 & 1,09 \\
TATA & $-0,07$ & $-0,06$ & $-0,12$ & $-0,03$ & $-0,02$ & $-0,06$ & $-0,02$ & $-0,03$ & $-0,05$ & $-0,06$ & 0,00 & $-0,02$ \\
LVGI & 0,97 & 0,95 & 1,10 & 0,97 & 1,14 & 0,99 & 0,96 & 0,97 & 1,04 & 1,06 & 0,98 & 0,96
\end{tabular}




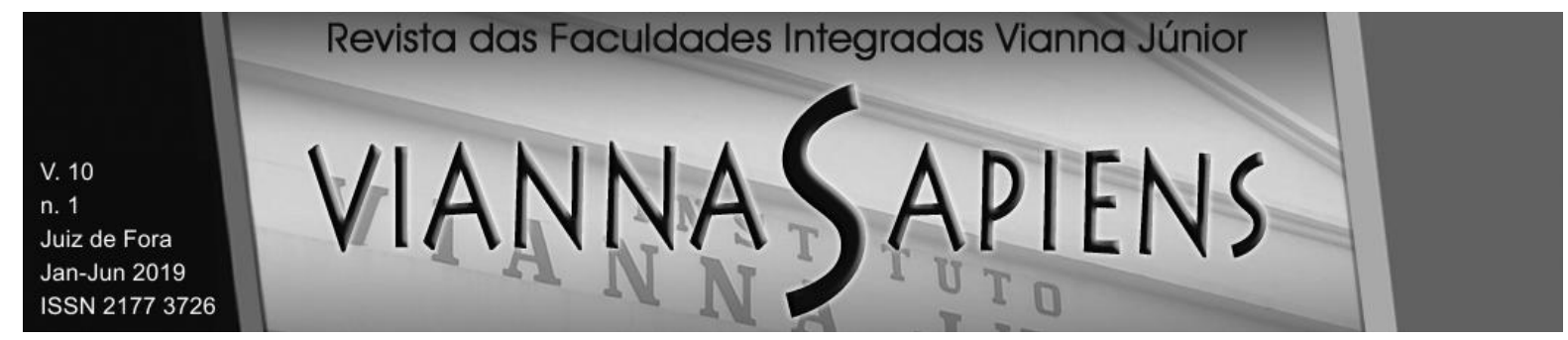

\begin{tabular}{ll|l|l|l|l|l|l|l|l|l|l|l}
\hline M-score & $-2,62$ & $-2,66$ & $-2,98$ & $-2,61$ & $-3,15$ & $-2,77$ & $-2,61$ & $-2,57$ & $-3,04$ & $-2,08$ & $-2,73$ & $-2,59$ \\
\hline Alfa & 0,44 & $-0,15$ & 0,11 & $-0,11$ & 0,25 & 0,28 & 0,51 & 0,17 & $-0,36$ & 0,35 & 0,32 & 0,04 \\
\hline Beta & 0,78 & 0,86 & 0,89 & 0,64 & 0,72 & 0,58 & 0,29 & 1,10 & 0,74 & 1,14 & 0,54 & $: 0,71$ \\
\hline Ibovespa & $33 \%$ & $144 \%$ & $-41 \%$ & $83 \%$ & $1 \%$ & $-18 \%$ & $7 \%$ & $-15 \%$ & $-3 \%$ & $-13 \%$ & $39 \%$ & $: 27 \%$ \\
\hline Empresa & $94 \%$ & $15 \%$ & $-31 \%$ & $32 \%$ & $30 \%$ & $22 \%$ & $74 \%$ & $-6 \%$ & $-33 \%$ & $14 \%$ & $54 \%$ & $24 \%$ \\
\hline
\end{tabular}

Fonte: Autores

A Sabesp também apresenta apenas no ano de 2015 com indicador positivo. Seu índice de DSRI e AQI são os mais elevados da série analisada. Assim, o índice de vendas diárias e recebíveis e o índice de qualidade dos ativos melhorou.. Interessante observar que a empresa passa a apresentar risco superior ao do mercado no ano em que o modelo detecta indício e, ainda, no ano em que o índice Beneish M-Score atinge seu segundo maior nível na série.

O Beta demonstra um risco inferior ao de mercado na maioria dos anos, sendo descorrelacionado ao de mercado em algumas situações e, em 2013 e 2015, supera o risco de mercado.

O Alfa apresentou geração de excesso de retorno em relação ao lbovespa em 2015 e 2016. Na série, o Alfa não apresenta tendência definida.

Nas Demonstrações Financeiras da Companhia, 2015, é explicada a situação hídrica do Estado de São Paulo em 2015, um programa de bônus àqueles que consumissem menos água e passivos em moeda estrangeira (dólar). Desta forma, a receita não sobe na magnitude dos demais indicadores financeiros, ocasionando o impacto em seu resultado.

\section{Companhia de Saneamento do Paraná (Sanepar)}

Tabela 16 - Índices Beneish M-Score, Alfa e Beta da Sanepar

\begin{tabular}{ll|l|l|l|l|l|l|l|l|l|l|l}
\hline SANEPAR & 2006 & 2007 & 2008 & 2009 & 2010 & 2011 & 2012 & 2013 & 2014 & 2015 & 2016 & 2017 \\
\hline DSRI & 0,96 & 0,99 & 1,01 & 1,02 & 1,26 & 0,85 & 1,08 & 1,01 & 0,95 & 0,91 & 1,08 & 1,02 \\
GMI & 0,94 & 0,99 & 0,98 & 0,98 & 1,00 & 1,06 & 1,05 & 0,98 & 0,95 & 0,95 & 1,07 & 1,02 \\
AQI & 1,29 & 0,97 & 1,02 & 1,07 & 1,09 & 0,86 & 1,26 & 1,04 & 0,93 & 0,85 & 1,16 & 1,10 \\
SGI & 1,03 & 1,06 & 1,06 & 1,07 & 1,07 & 1,18 & 1,22 & 1,12 & 1,10 & 1,14 & 1,17 & 1,11 \\
DEPI & 1,01 & 1,06 & 0,00 & 0,00 & 0,00 & 0,00 & 0,00 & 0,00 & 0,00 & 0,00 & 0,00 & 0,00
\end{tabular}




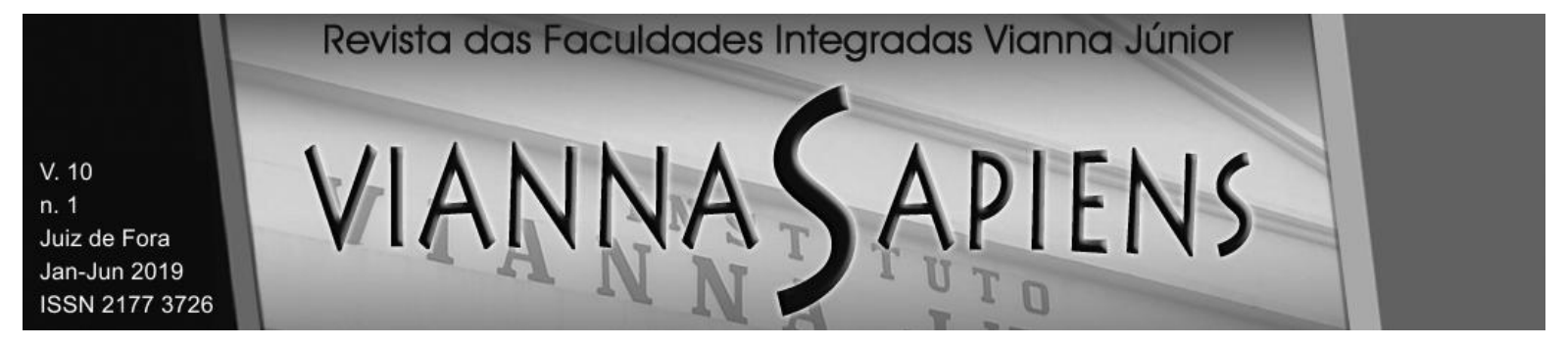

\begin{tabular}{ll|l|l|l|l|l|l|l|l|l|l|l} 
SGAI & 1,06 & 0,92 & 1,01 & 0,96 & 0,00 & 0,00 & 0,00 & 0,00 & 0,00 & 0,00 & 0,00 & 0,00 \\
TATA & $-0,06$ & $-0,07$ & $-0,07$ & $-0,07$ & $-0,06$ & $-0,06$ & $-0,06$ & $-0,06$ & $-0,05$ & $-0,05$ & $-0,05$ & $-0,07$ \\
LVGI & 0,98 & 0,97 & 1,37 & 0,99 & 1,01 & 0,99 & 1,04 & 0,78 & 1,05 & 0,99 & 1,00 & 1,00 \\
\hline M-score & $-2,69$ & $-2,76$ & $-3,00$ & $-2,79$ & $-2,39$ & $-2,69$ & $-2,33$ & $-2,51$ & $-2,67$ & $-2,72$ & $-2,33$ & $-2,56$ \\
\hline Alfa & 0,22 & $-0,22$ & $-0,05$ & 0,33 & 0,14 & 0,52 & 0,70 & $-0,15$ & $-0,11$ & $-0,48$ & 0,77 & $-0,03$ \\
\hline Beta & 0,22 & 0,59 & 0,75 & 0,29 & 0,80 & 0,25 & 0,19 & 0,37 & 0,45 & 0,32 & 0,63 & 0,96 \\
\hline Ibovespa & $33 \%$ & $44 \%$ & $-41 \%$ & $83 \%$ & $1 \%$ & $-18 \%$ & $7 \%$ & $-15 \%$ & $-3 \%$ & $-13 \%$ & $39 \%$ & $27 \%$ \\
\hline Empresa & $46 \%$ & $2 \%$ & $-42 \%$ & $80 \%$ & $16 \%$ & $66 \%$ & $106 \%$ & $-21 \%$ & $-7 \%$ & $-36 \%$ & $268 \%$ & $16 \%$ \\
\hline Fonte: Autores
\end{tabular}

A Sanepar não apresenta nenhum indício de gerenciamento de resultados. 0 comportamento de suas ações em relação ao lbovespa reflete um risco inferior ao de mercado ou descorrelacionado.

O Alfa não apresenta tendência clara, com desvio padrão de 0,37 e média de 0,14 .

Transmissora Aliança de Energia Eletrica S.A (Taesa)

Tabela 17 - Índices Beneish M-Score, Alfa e Beta da Taesa

\begin{tabular}{ll|l|l|l|l|l|l|l|l|l|l|l}
\hline TAESA & 2006 & 2007 & 2008 & 2009 & 2010 & 2011 & 2012 & 2013 & 2014 & 2015 & 2016 & 2017 \\
\hline DSRI & 0,00 & 0,00 & 0,00 & 0,00 & 0,00 & 1,13 & 0,82 & 0,88 & 0,94 & 1,03 & 1,24 \\
GMI & 1,00 & 0,00 & 0,00 & 0,00 & 0,00 & 0,99 & 0,93 & 1,03 & 1,04 & 0,98 & 0,97 \\
AQI & 1,20 & 1,12 & 1,05 & 0,87 & 1,07 & 0,79 & 1,25 & 1,00 & 0,97 & 1,00 & 0,99 \\
SGI & 1,62 & 0,00 & 0,00 & 0,00 & 0,00 & 0,80 & 1,67 & 1,09 & 1,03 & 0,89 & 0,71 \\
DEPI & 0,00 & 0,00 & 0,00 & 0,00 & 0,00 & 0,92 & 0,72 & 0,72 & 1,04 & 1,72 & 0,94 \\
SGAI & 1,11 & 0,00 & 0,00 & 0,00 & 0,00 & 3,36 & 0,84 & 0,78 & 1,39 & 1,15 & 1,57 \\
TATA & 0,17 & 0,09 & 0,07 & 0,09 & $-0,04$ & $-0,04$ & $-0,02$ & $-0,09$ & $-0,08$ & $-0,09$ & $-0,11$ \\
LVGI & 0,67 & 5,84 & 0,87 & 1,93 & 1,34 & 0,83 & 1,02 & 1,00 & 0,99 & 0,96 & 0,94 \\
\hline M-score & $-1,97$ & $-5,88$ & $-4,38$ & $-4,71$ & $-5,02$ & $-3,16$ & $-2,11$ & $-2,92$ & $-2,95$ & $-2,93$ & $-3,13$ \\
\hline Alfa & 10,06 & $-0,08$ & 0,44 & $-0,23$ & 0,35 & 0,61 & $-0,03$ & 0,10 & 10,04 & 10,15 & $1-0,05$ \\
\hline Beta & 10,70 & 0,43 & 0,36 & $-0,14$ & $-0,03$ & $-0,04$ & 0,44 & 0,40 & 0,59 & 0,38 & $: 0,52$ \\
\hline Ibovespa & $33 \%$ & $44 \%$ & $-41 \%$ & $83 \%$ & $1 \%$ & $-18 \%$ & $7 \%$ & $-15 \%$ & $-3 \%$ & $-13 \%$ & $39 \%$ & $27 \%$ \\
\hline Empresa & $135 \%$ & $-25 \%$ & $87 \%$ & $-15 \%$ & $57 \%$ & $94 \%$ & $-7 \%$ & $20 \%$ & $0 \%$ & $42 \%$ & $12 \%$ \\
\hline Fon:Auto
\end{tabular}

Fonte: Autores 


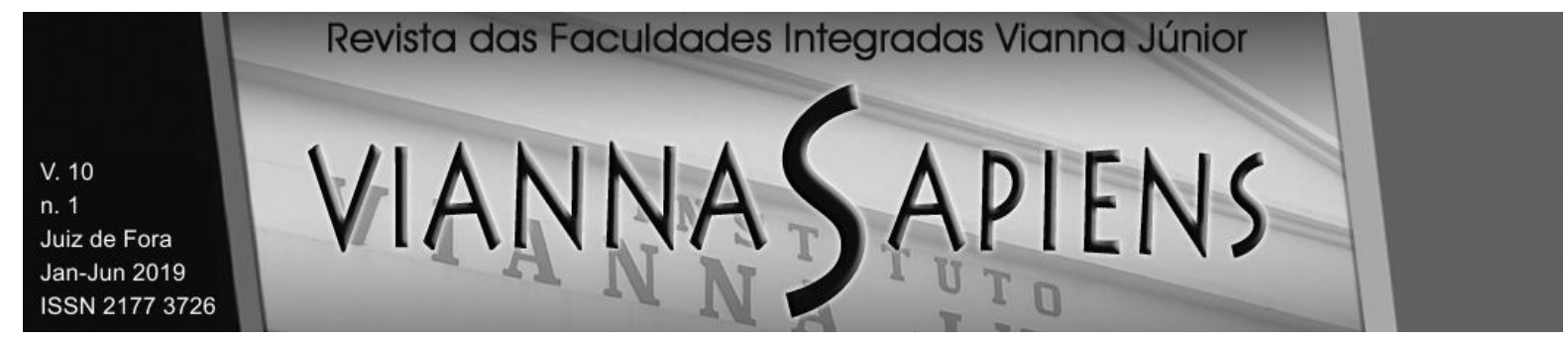

A Taesa, abriu capital em outubro de 2006. Apresenta indício de gerenciamento de resultados em 2007 e 2013 Nestes dois anos, seus índice AQI e SGI apresentaram seus máximos. Beneish (1999) destaca que se AQI for maior que 1 , isso indica que a empresa aumentou potencialmente seu envolvimento no diferimento de custos ou aumentou seus ativos intangíveis e gerou ganhos de gerenciamento. Um aumento neste índice pode representar despesas adicionais que estão sendo capitalizadas para preservar a lucratividade e, portanto, adiar custos. Ainda o crescimento de vendas (aumento de vendas - SGI), pode mostrar que a empresa não está apresentando crescimento de modo sustentável.

Em relação ao risco da empresa, após um Índice Beneish M-Score superior a -2,22, não houve grande impacto e a empresa ficou não correlacionada ou pouco correlacionada com os retornos do mercado. Assim como o Alfa, que não apresentou tendência clara após os eventos, com desvio padrão de 0,24 e média de 0,13 .

\section{Telecomunicações Brasileiras S.A (Telebras)}

Tabela 18 - Índices Beneish M-Score, Alfa e Beta da Telebras

\begin{tabular}{|c|c|c|c|c|c|c|c|c|c|c|c|c|}
\hline $\begin{array}{l}\text { TELE- } \\
\text { BRAS }\end{array}$ & 2006 & 2007 & 2008 & 2009 & 2010 & 2011 & 2012 & 2013 & 2014 & 2015 & 2016 & 2017 \\
\hline$\overline{D S R I}$ & 0,00 & 0,00 & 0,00 & 0,00 & 0,00 & 0,00 & 0,05 & 0,08 & 1,21 & 0,78 & 0,99 & 0,83 \\
\hline GMI & 0,00 & 0,00 & 0,00 & 0,00 & 0,00 & 0,00 & $-4,39$ & 0,14 & 11,29 & 0,54 & 0,71 & 0,89 \\
\hline AQI & 1,27 & 1,06 & 0,55 & 1,00 & 0,89 & 0,47 & 1,01 & 1,02 & 0,66 & 0,85 & 1,20 & 0,93 \\
\hline SGI & 0,00 & 0,00 & 0,00 & 0,00 & 0,00 & 0,00 & 23,15 & 18,43 & 0,74 & 1,45 & 1,24 & 1,31 \\
\hline DEPI & 0,00 & 0,00 & 0,00 & 0,00 & 0,00 & 0,00 & 0,61 & 1,25 & 6,17 & 0,70 & 0,64 & 1,05 \\
\hline SGAI & 0,00 & 0,00 & 0,00 & 0,00 & 0,00 & 0,00 &, 00 & 1,16 & 26 & 0,32 & 1,56 &, 78 \\
\hline TATA & 0,81 & 0,00 & 0,06 & 0,04 & 0,02 & 0,04 & 0,01 & 0,01 & 0,02 & 0,07 & 0,03 & 0,06 \\
\hline LVGI & 2,71 & 1,07 & 0,58 & 1,05 & 1,01 & 1,04 & 0,68 & 1,23 & 1,11 & 1,09 & 1,07 & 0,71 \\
\hline M-score & $-1,44$ & $-4,76$ & $-4,53$ & $-4,57$ & $-4,71$ & $-4,78$ & 13,85 & 11,75 & 3,21 & $-2,21$ & $-2,35$ & $-2,04$ \\
\hline Alfa & 0,71 & 4,06 & 0,65 & 1,23 & 1,15 & 0,99 & $-0,89$ & $-0,81$ & $-0,63$ & 1,34 & 1,25 & 0,50 \\
\hline Beta & 2,92 & $-0,12$ & 0,56 & $-0,55$ & $-1,54$ & 0,53 & 0,19 & 0,43 & $-0,68$ & 1,68 & $-0,51$ & $-0,21$ \\
\hline Ibovespa & $33 \%$ & $44 \%$ & $-41 \%$ & $83 \%$ & $1 \%$ & $-18 \%$ & $7 \%$ & $-15 \%$ & $-3 \%$ & $-13 \%$ & $39 \%$ & $27 \%$ \\
\hline Empresa & $50 \%$ & $800 \%$ & $-51 \%$ & $135 \%$ & $119 \%$ & $120 \%$ & $-66 \%$ & $-64 \%$ & $-52 \%$ & 14\% & $8 \%$ & $55 \%$ \\
\hline
\end{tabular}




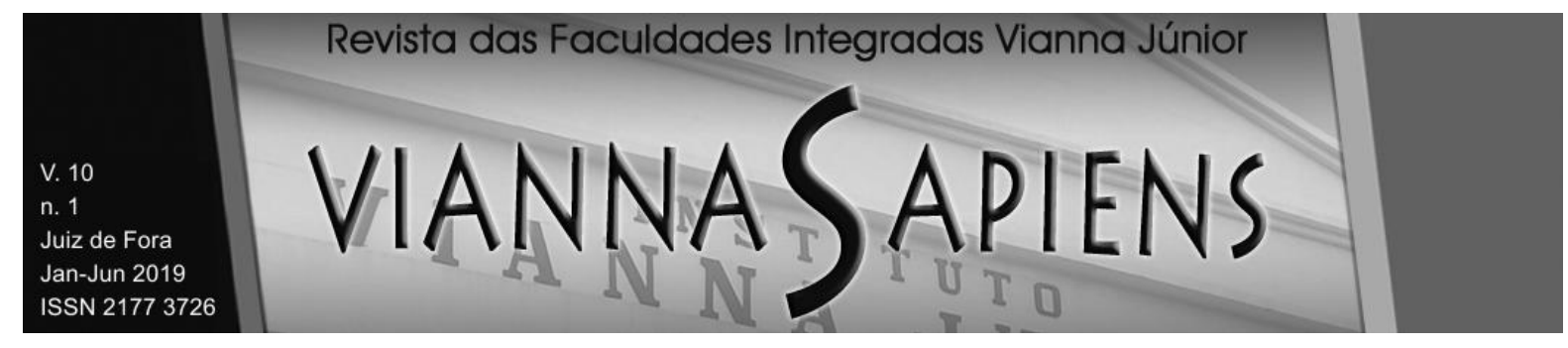

A Telebrás apresentou consecutivos anos de indicação de gerenciamento de resultados pelo modelo de $\mathrm{M}$ Beneish. $\mathrm{O}$ comportamento de suas ações em relação ao Ibovespa não se manteve constante, não sendo possível detectar padrões de risco em relação ao mercado. À exceção de 2006, o Alfa apresentou valor negativo nos anos em que o Índice Beneish M-Score foi positivo para gerenciamento, com desvio padrão de 1,95 e média de 0,76.

Em seu Relatório da Administração, a Telebras discorre que foi encarregada pelo Governo Federal de disponibilizar sua infraestrutura para o atendimento dos serviços de mídia para a Copa das Confederações (2013) e da Copa do Mundo (2014), com altíssimo grau de disponibilidade. Os investimentos se intensificaram para a realização de novas operações até 2017 , com aportes do controlador em todos estes anos (TELEBRAS, 2019).

Entre 2012 e 2018 teve uma deterioração de valor em 105\%, enquanto o Ibovespa apresentou valorização de $41 \%$.

\section{CONCLUSÃO}

Ao longo do estudo, a hipótese inicial, de que as empresa de economia mista não realizavam gerenciamento de resultados, não se mostrou válida. $O$ fato de haver concentração de propriedade pelo Estado nas empresas selecionadas não minimizou a possibilidade de ocorrência de gerenciamento de resultados pelo modelo de Beneish.

No caso das sociedades de economia mista, o Estado exerce importante papel de fomento ao desenvolvimento econômico. Nas empresas em que ele controla, apenas três não tiveram indícios de gerenciamento de resultados detectados (BB, Banese e Sanepar). As três obtiveram retorno superior ao do Ibovespa no período analisado.

Nas empresas que apresentaram indícios apenas uma vez (Celesc, Copasa, Copel, Petrobras e Sabesp) nota-se que nem sempre superam o Ibovespa. Banrisul, Cesp, EMAE e Taesa apresentaram indícios duas vezes por situações diversas e 


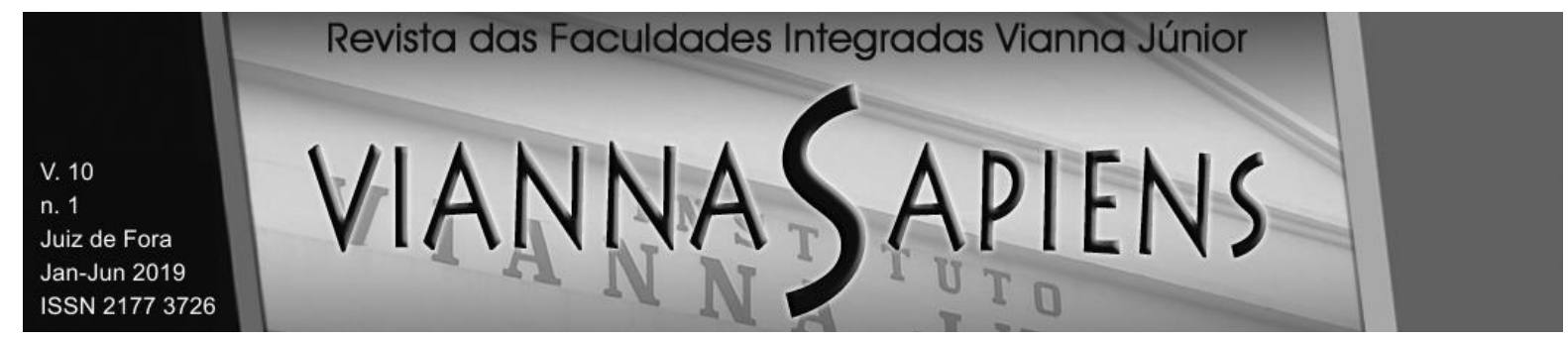

em anos não consecutivos, sendo que apenas a Cesp não obteve retorno no período superior ao lbovespa.

CEB, CEEE, Cemig, Eletrobrás e Telebrás apresentaram mais de dois indícios. À exceção da Eletrobrás, todas as empresas apresentam-se não atraentes ao investidor nos últimos anos. Ao analisar suas demonstrações, diversas situações de fragilidade são observadas. Cumpriria ao controlador rever o estilo de gestão e analisar os erros cometidos nas gestões passadas.

Desta forma, ao verificar as empresas e seus resultados nos anos em que 0 indício é detectado, percebe-se a necessidade da sociedade e do Estado acompanharem o resultado dessas empresas sob a ótica de investidor, para não se posicionarem como consumidor ou utilizarem as empresas como instrumento de política.

Há limitações no modelo deBeneish (1999), sendo as principais que as distorções podem ter uma origem alternativa, que deve ser apurada nos relatórios financeiros.Ainda, o modelo só se aplica em empresas de capital aberto. Finalmente, os coeficientes angulares da equação do Beneish M-Score são fixos.

A realização de outras pesquisas sobre o tema possivelmente contribuirá para que outros fatores sejam conhecidos e detalhados, o que é uma condição imprescindível tanto para a prevenção quanto para a detecção da manipulação de resultados.

\section{REFERÊNCIAS}

ANH, Nguyen Huu; LINH, Nguyen HaN. Using the M-score Model in Detecting Earnings Management: Evidence from Non-Financial Vietnamese Listed Companies. Journal of Science: Economics and Business. Vietnã, v. 32, n.2, p 14-23, jun. 2016.

ASSOCIAÇÃO BRASILEIRA DE NORMAS TÉCNICAS. NBR 6023: informação e documentação: Referências - Elaboração. Rio de Janeiro, 2002.

B3. Vem pra a bolsa. 2017. Disponível em: <http://vemprabolsa.com.br/2017/03/29/o-que-e-free-float/> Acesso em: 13 jun. 2018. 


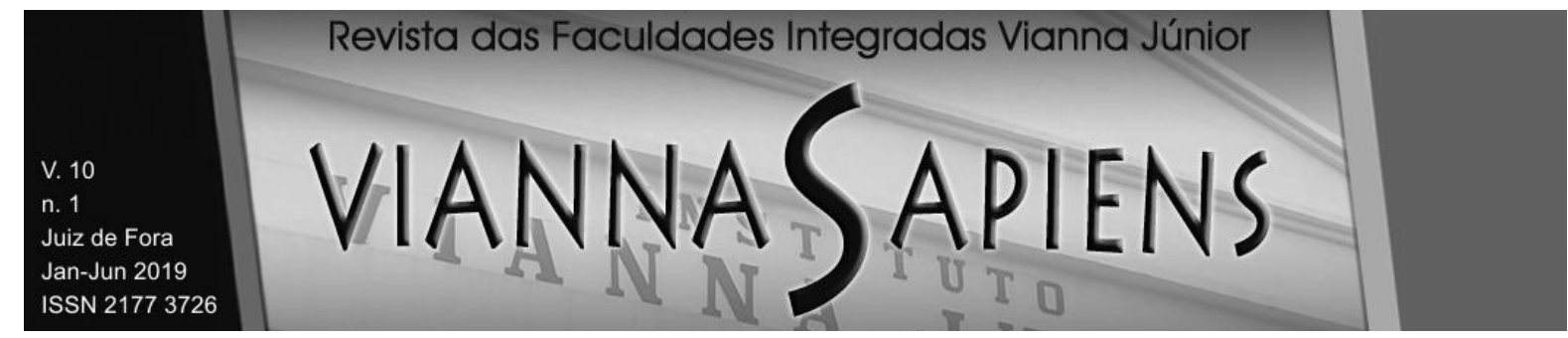

BENEISH, Messod Daniel. The Detection of Earning Manipulation. Financial Analysts Journal. Estados Unidos, v. 55, p. 24-36, set. 1999.

BENEISH, Messod Daniel; NICHOLS, Craig. Earnings Quality and Future Returns: The Relation between Accruals and the Probability of Earnings Manipulation. Indiana, mai. 2005. Disponível em: <http://dx.doi.org/10.2139/ssrn.725162 > Acesso em: 13 jun. 2018.

BENEISH, Messod Daniel; NICHOLS, Craig. Identifying Overvalued Equity. Johnson School Research. Indiana, n. 9, mai. 2009. Disponível em: <http://dx.doi.org/10.2139/ssrn.1134818> Acesso em: 07 jun. 2018.

BENEISH, Messod Daniel; LEE, Charles; NICHOLS, Craig. Fraud Detection and Expected Returns. Estados Unidos, fev. 2012. Disponível em: $<$ https://ssrn.com/abstract=1998387 or http://dx.doi.org/10.2139/ssrn.1998387>. Acesso em: 07 jun. 2018.

BENEISH, Messod Daniel; LEE, Charles; NICHOLS, Craig.Earnings Manipulation and Expected Returns. Financial Analysts Journal. Indiana, v. 69, n. 2, abr. 2013.

CORSI, C.;BERARDINO, D.; CIMBRINI, T.. Beneish M-Score and detection of earnings management in Italian SMEs. Ratio Mathematica. Teramo, v.28, p. 65-83, 2015. ISSN 1592-7415.Disponível em: <http://eiris.it/ojs/index.php /ratiomathematica/article/view/28/pdf>. Acesso em: 02 mar. 2018.

DICHEV, Ilia; GRAHAM John; HARVEY, Campbell; e RAJGOPAL, Shiva. Earnings quality: Evidence from the field. Journal of Accounting and Economics. Nova lorque, v.2, n. 56, p. 1-33, dez. 2013. Disponível em: https://doi.org/10.1016/.j.jacceco.2013.05.004

GIL, A. C. Como Elaborar Projetos de Pesquisa. 5. ed. São Paulo: Atlas, 2010. Métodos e Técnicas de Pesquisa Social. 6. ed. São Paulo: Atlas, 2014. 


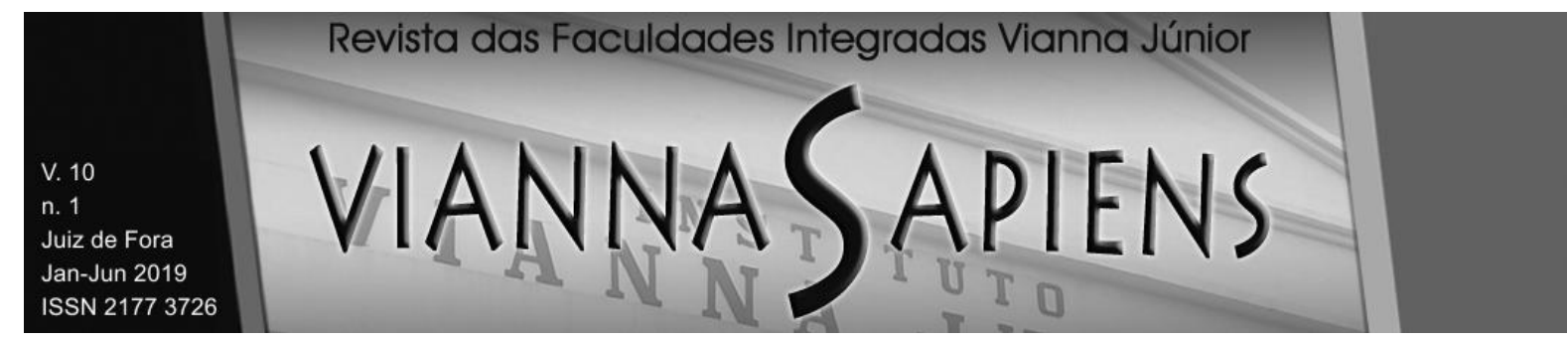

HASAN, Shamimul;OMAR, N.; BARNES, Normah; HANDLEY-SCHANLER, Paul. A cross-country study on manipulations in financial statements of listed companies:

Evidence from Asia, Journal of Financial Crime. Asia, v. 24, n. 4, p. 656-677, 2017. Disponível em <https://doi.org/10.1108/JFC-07-2016-0047> Acesso em: 07 jan. 2019.

IN'AIRAT, Mohammad. The Role of Corporate Governance in Fraud Reduction - A Perception Study in the Saudi Arabia Business Environment . Journal of

Accounting and Finance. Arábia Saudita, v. 15, n. 2, p.119-128, abr. 2015

ISMAIL, Vinola; WITARNO, Kiki. Analysis the Effect of Company's Fundamental Characteristics and Real Earnings Management to Stock Return Moderated by Audit Quality. OIDA International Journal of Sustainable Development. Texas, v. 09, n. 02, p. 23-44, mar. 2016. Disponível em: https://ssrn.com/abstract=2739785. Acesso em: 07 abr. 2018.

KASSEM, Rasha; HIGSON, Andrew. Financial Reporting Fraud: Are Standards" Setters and External Auditors Doing Enough? International Journal of Business and Social Science. Estados Unidos, v. 3 n. 19, p. 283-290, out. 2012. Disponível em:<http://ijbssnet.com /journals/Vol_3_No_19_October_2012/32.pdf>. Acesso em: 07 abr. 2018.

KONRAHT, Jonatan; SOUTES, Dione; ALENCAR, Roberta. Relação entre a Governança Corporativa e o Alisamento de Resultados em Empresas Brasileiras. Revista de Contabilidade e Controladoria, ISSN 1984-6266. Universidade Federal do Paraná. Curitiba, v. 8, n.1, p. 47-62, jan./abr. 2016.

MAHAMA, Muntari. Detecting Corporate Fraud and Financial Distress using the Altman and Beneish Models. International Journal of Economics, Commerce and Management. Reino Unido, v. 3, n. 1, p1-18, jan. 2015. ISSN 23480386

OMAR Normah;KOYA,Ridzuan Kunji;SANUSI,Zuraidah Mohd.; SHAFIE, NurAima. Financial Statement Fraud: A Case Examination Using Beneish Model and Ratio Analysis. International Journal of Trade, Economics and Finance. Malásia, v.5, n.2, p. $184-186,2014$.

PINHO, Clóvis Alberto; RIBEIRO, Marcia Carla Pereira. Corrupção e compliance nas empresas públicas e sociedades de economia mista: racionalidade das disposições 


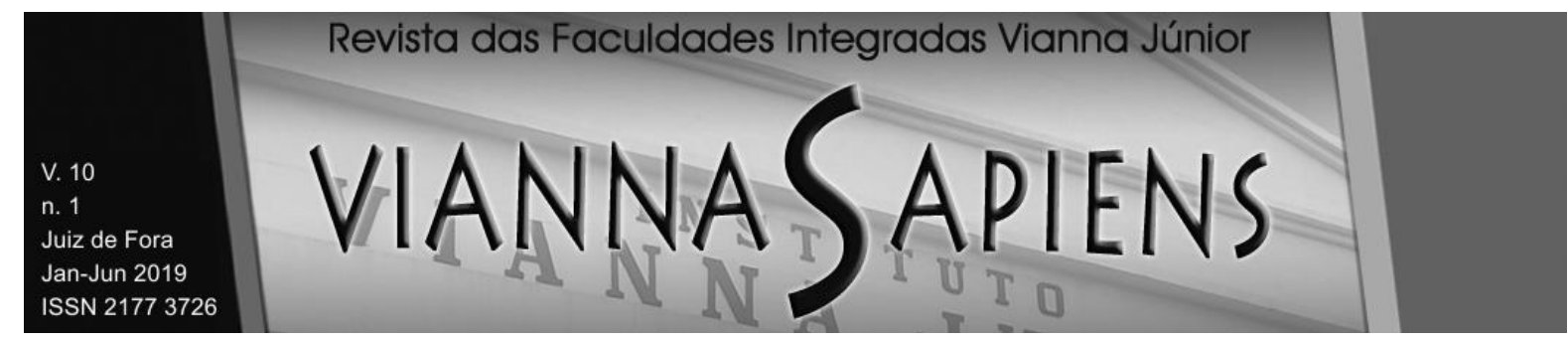

da Lei de Empresas Estatais (Lei o 13.303/2016). Revista de Direito

Administrativo. Rio de Janeiro, v. 277, n. 1, p. 241-272, 2018. Disponível em:< htp://dx.doi.org/10.12660/ rda.v277.2018.74808, Acesso em: 08 set. 2018.

REPOUSIS,Spyridon. Using Beneish model to detect corporate financial statement fraud in Greece, Journal of Financial Crime. Grécia, v. 23, n. 4, out. 2016.

Disponível em:<https://doi.org/10.1108/JFC-11-2014-0055>. Acesso em: 15 dez. 2018.

ROY, Chinmoy; DEBNATH, Pranesh. Earnings Management Practices in Financial Reporting of Public Enterprises in India: An Empirical Test with MScore. Tripura, jan. 2015. Disponível em:<https://ssrn.com/abstract=2551713 or http://dx.doi.org/10.2139/ssrn.2551713 >. Acesso em: 07 abr. 2018.

TARJO, Nurul. Application of Beneish M-Score Models and Data Mining to Detect Financial Fraud. In: Second Global Conference on Business and Social Science. Bali, 2015. Disponível em:

<https://www.sciencedirect.com/science/article/pii/S1877042815054622>. Acesso em: 15 dez. 2018.

WARSHAVSKY, Mark. Analyzing Earnings Quality as a Financial Forensic Tool. Financial Valuation and Litigation Expert Journal. Nova lorque, v.39, p. 16-20, out. 2012. Disponível em: <http://www.gettrymarcus.com/wpcontent/uploads/pdfs/MW-Analyzing-Earnings-Quality-as-a-Financial-ForensicsTool.pdf>. Acesso em: 07 abr. 2018.

Recebido em 29/05/2019

Publicado em 12/07/2019 